\title{
Betulinic acid inhibits stemness and EMT of pancreatic cancer cells via activation of AMPK signaling
}

\author{
LIANKANG SUN ${ }^{1 *}$, JUNYU CAO $^{1 *}$, KE CHEN $^{1}$, LIANG CHENG $^{1}$, CANCAN ZHOU $^{1}$, BIN YAN $^{1}$,

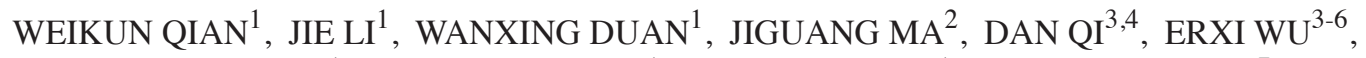 \\ ZHENG WANG $^{1}$, QINGGUANG LIU ${ }^{1}$, QINGYONG MA ${ }^{1}$ and QINHONG XU ${ }^{7}$
}

\begin{abstract}
Departments of ${ }^{1}$ Hepatobiliary Surgery and ${ }^{2}$ Anesthesiology, First Affiliated Hospital of Xi'an Jiaotong University, Xi'an, Shaanxi 710061, P.R. China; ${ }^{3}$ Department of Neurosurgery, Baylor Scott \& White Health, Temple, TX 78508;

${ }^{4}$ Neuroscience Institute, Baylor Scott \& White Health, Temple, TX 76502; ${ }^{5}$ Department of Surgery,

Texas A\&M University College of Medicine, College Station, TX 76504; ${ }^{6}$ Department of Pharmaceutical Sciences, Texas A\&M University College of Pharmacy, College Station, TX 77843, USA; ${ }^{7}$ Department of Geriatric Surgery, First Affiliated Hospital of Xi'an Jiaotong University, Xi'an, Shaanxi 710061, P.R. China
\end{abstract}

Received May 9, 2018; Accepted September 26, 2018

DOI: 10.3892/ijo.2018.4604

\begin{abstract}
Cancer stem cells (CSCs), which are found in various types of human cancer, including pancreatic cancer, possess elevated metastatic potential, lead to tumor recurrence and cause chemoradiotherapy resistance. Alterations in cellular bioenergetics through the regulation of 5 ' adenosine monophosphate-activated protein kinase (AMPK) signaling may be a prerequisite to stemness. Betulinic acid (BA) is a well-known bioactive compound with antiretroviral and anti-inflammatory potential, which has been reported to exert anticancer effects on various types of cancer, including pancreatic cancer. The present study aimed to investigate whether BA could inhibit pancreatic CSCs via regulation of AMPK signaling. The proliferation of pancreatic cancer cells was examined by MTT and colony formation assays. The migratory and invasive abilities of pancreatic cancer cells were assessed using wound-scratch and Transwell invasion assays. In addition, the expression levels of candidate genes were measured by reverse transcription-quantitative polymerase
\end{abstract}

Correspondence to: Dr Qinhong Xu, Department of Geriatric Surgery, First Affiliated Hospital of Xi'an Jiaotong University, 277 West Yanta Road, Xi'an, Shaanxi 710061, P.R. China

E-mail: xuqinhong8401@163.com

Professor Qingyong Ma, Department of Hepatobiliary Surgery, First Affiliated Hospital of Xi'an Jiaotong University, 277 West Yanta Road, Xi'an, Shaanxi 710061, P.R. China

E-mail: qyma56@xjtu.edu.cn

*Contributed equally

Key words: betulinic acid, pancreatic cancer, cancer stem cells, epithelial-mesenchymal transition, 5' adenosine monophosphateactivated protein kinase, gemcitabine chain reaction and western blotting. The results revealed that BA inhibited the proliferation and tumorsphere formation of pancreatic cancer cells, suppressed epithelial-mesenchymal transition (EMT), migration and invasion, and reduced the expression of three pluripotency factors [SRY-box 2 (Sox2), octamer-binding protein 4 (Oct4) and Nanog]. Furthermore, immunohistochemical analysis confirmed that there was a significant inverse association between the expression levels of phosphorylated (P)-AMPK and Sox 2 in pancreatic cancer, and it was revealed that BA may activate AMPK signaling. Notably, knockdown of AMPK reversed the suppressive effects of BA on EMT and stemness of pancreatic cancer cells. In addition, BA reversed the effects of gemcitabine on stemness and enhanced the sensitivity of pancreatic cancer cells to gemcitabine. Collectively, these results indicated that BA may effectively inhibit pluripotency factor expression (Sox2, Oct4 and Nanog), EMT and the stem-like phenotype of pancreatic cancer cells via activating AMPK signaling. Therefore, BA may be considered an attractive therapeutic candidate and an effective inhibitor of the stem-like phenotype in pancreatic cancer cells. Further investigation into the development of BA as an anticancer drug is warranted.

\section{Introduction}

Pancreatic cancer is a highly malignant tumor of the digestive system with a 5-year survival rate of $<7 \%$; the incidence rate of pancreatic cancer is almost equal to its mortality rate (1). The majority of patients with pancreatic cancer lack apparent symptoms until it has evolved into an advanced stage. Therefore, only $20 \%$ of patients with pancreatic cancer have the opportunity for radical resection (2). Even among those who undergo potentially curative resection, the majority of patients will eventually relapse, and the 5-year survival rate of patients who undergo a complete resection is $<25 \%$ (3). Autopsy cases have revealed that $\sim 90 \%$ of patients with pancreatic cancer also have distant metastases (4); therefore, it is imperative to 
clarify the mechanism underlying its early metastasis and high recurrence rate, in order to improve therapeutic efficacy.

It has previously been reported that there is a subpopulation of cells in pancreatic ductal adenocarcinomaå(PDAC), which is the most common type of pancreatic cancer, that exhibits stem cell-like traits; these cells are termed pancreatic cancer stem cells (PCSCs), and have the capacity of self-renewal and differentiation into heterogeneous cancer cells. PCSCs serve a key role in tumor initiation, invasion, metastasis and therapeutic resistance, as well as in local recurrence following curative resection. Therefore, the elimination of PCSCs from pancreatic cancer is considered an effective strategy for the treatment of this highly refractory malignancy (5-7). Although additional molecular markers of CSCs are still being discovered, three transcription factors; namely, SRY-box 2 (Sox2), octamer-binding protein 4 (Oct4) and Nanog, have been reported as master mediators of pluripotency (8). Epithelial-mesenchymal transition (EMT) is characterized by the loss of intercellular adhesion and decreased expression of epithelial markers, including E-cadherin, and enhanced expression of mesenchymal markers, such as vimentin (9). EMT has an important role in tumor invasion, metastasis and therapeutic resistance. Notably, a direct connection has been reported between EMT and the acquirement of stem cell-like properties (10), as EMT generates neoplastic stem cells. In addition, neoplastic stem cells tend to express higher levels of the molecular markers of EMT during metastasis (10). Furthermore, non-PCSCs can be converted into PCSCs by introducing ectopic expression of zinc finger E-box binding homeobox 1, a key transcriptional factor associated with EMT (11), which facilitates cell invasion and treatment resistance to enhance the malignant phenotype (12). This further highlights the close association between the properties of CSCs and EMT.

$5^{\prime}$ adenosine monophosphate-activated protein kinase (AMPK) is a heterotrimeric complex that consists of catalytic $\alpha$-subunits, and regulatory $\beta$ - and $\gamma$-subunits. It exerts a crucial role in regulating energy metabolism in cancer as an energy sensor (13). AMPK activation inhibits energy consumption under nutrient deprivation, leading to the suppression of protein synthesis and cellular proliferation (14). Previous studies have confirmed that AMPK signaling is also involved in regulating various pathological aspects of fibrosis, and modulates migration and invasion (15-19). Alteration of cellular bioenergetics through the regulation of AMPK signaling may be a prerequisite to stemness (20). Recently, Sengupta et al revealed that activation of tumor suppressor-liver kinase B1 by honokiol subsequently enhances AMPK phosphorylation, which in turn restricts the recruitment of signal transducer and activator of transcription 3 (STAT3) to the promoter regions of Sox 2, Oct4 and Nanog, leading to inhibition of the stem-like phenotype in breast cancer (8). Similarly, methylisoindigo, which is a natural product of indirubin and a derivative of isoindigo, is able to kill PCSCs by modulating cell metabolism via activation of AMPK in PDAC (21). Metformin is an activator of AMPK, which also serves important roles in targeting PCSCs via regulating metabolism and microRNA expression $(22,23)$. Although AMPK signaling is involved in the stemness of pancreatic cancer, its explicit mechanism has not been completely clarified and there is currently a lack of effective drugs that preferentially kill PCSCs via the modulation of AMPK signaling.

Betulinic acid (BA) is a natural pentacyclic triterpene purified from bark, particularly bark from Betula sp., which exhibits a wide spectrum of pharmacological and biological activities. BA has been reported to exert antidepressive (24), anti-inflammatory $(25,26)$ and anti-acquired immune deficiency syndrome (AIDS) $(27,28)$ effects, and possesses hepatoprotective potential (29) and anticancer efficacy (30-32). It has previously been suggested that the combined use of BA and mithramycin A may effectively suppress angiogenesis, proliferation and invasion of pancreatic cancer through downregulation of SP1 (33). A previous study further verified that lamin B1 is a novel therapeutic target in BA-treated pancreatic cancer independent of SP1 signaling (34). BA may also effectively ameliorate non-alcoholic fatty liver disease (NAFLD) via activation of AMPK and modulation of calcium/calmodulin-dependent protein kinase kinase-AMPK-mammalian target of rapamycin (mTOR)-sterol regulatory element-binding protein 1 signaling (35). However, whether BA exerts anticancer effects on pancreatic cancer and the underlying mechanism of action remain elusive. Therefore, the present study aimed to demonstrate whether BA could inhibit the EMT and stemness of pancreatic cancer cells through regulating the expression of pluripotency-induced transcription factors (i.e. Sox2, Oct4 and Nanog) via the activation of AMPK signaling. In addition, the study aimed to elucidate the contribution of BA to pancreatic cancer therapy.

\section{Materials and methods}

Reagents and antibodies. BA, gemcitabine, 5-aminoimidazole-4-carboxamide 1- $\beta$-D-ribofuranoside (AICAR), dimethyl sulfoxide (DMSO) and MTT were purchased from Sigma-Aldrich; Merck KGaA (Darmstadt, Germany). BA and AICAR were initially dissolved in dimethyl sulfoxide at stock concentrations of $50 \mathrm{mM}$ and $2 \mathrm{M}$, respectively. Working concentrations for BA and AICAR were diluted immediately in culture medium prior to use. Human epidermal growth factor (EGF) and fibroblast growth factor (FGF) were purchased from PeproTech, Inc. (Rocky Hill, NJ, USA).The antibodies used in this study were as follows: Rabbit anti-Sox2 (1:1,000 dilution; cat. no. ab97959), anti-Oct4 (1:1,000 dilution; cat. no. ab18976) and anti-Nanog (1:1,000 dilution; cat. no. ab80892) (all from Abcam, Cambridge, UK), mouse anti- $\beta$-actin (1:10,000 dilution; cat. no. 19526; KangChen Bio-Tech, Inc., Shanghai, China), mouse anti-E-cadherin (1:1,000 dilution; cat. no. sc-71008), rabbit anti-cluster of differentiation (CD)133 (1:1,000 dilution; cat. no. sc-11406), mouse anti-aldehyde dehydrogenase (ALDH)1 (1:1,000 dilution; cat. no. sc-374149) and mouse anti-epithelial cell adhesion molecule (EpCAM) (1:1,000 dilution; cat. no. sc-66020) (all from Santa Cruz Biotechnology, Inc., Dallas, TX, USA), and rabbit anti-vimentin (1:800 dilution; cat. no. 12826), anti-AMPK (1:800 dilution; cat. no. 5831) and anti-phosphorylated (P)-AMPK (Thr172) (1:800 dilution; cat. no. 2535) (all from Cell Signaling Technology, Inc., Danvers, MA, USA).

Cell culture. The Mia PaCa-2 and Panc-1 human pancreatic cancer cell lines were purchased from the Type Culture 
Collection of the Chinese Academy of Sciences (Shanghai, China). Mia PaCa-2 and Panc-1 cells were cultured in Dulbecco's modified Eagle's medium (DMEM; Gibco; Thermo Fisher Scientific, Inc., Waltham, MA, USA) supplemented with $10 \%$ heat-inactivated fetal bovine serum (FBS) (HyClone; GE Healthcare Life Sciences, Logan, UT, USA), $100 \mathrm{U} / \mathrm{ml}$ penicillin and $100 \mu \mathrm{g} / \mathrm{ml}$ streptomycin (Gibco; Thermo Fisher Scientific, Inc.). All cells were cultured in a humidified atmosphere at $37^{\circ} \mathrm{C}$ containing $5 \% \mathrm{CO}_{2}$.

Cell viability assay. Mia PaCa-2 and Panc-1 cells were seeded into 96-well plates at a density of $5 \times 10^{3}$ cells/well and treated with various concentrations of BA $(0,12.5,25,50,100$ and $200 \mu \mathrm{M}$ ) for 24,48 and $72 \mathrm{~h}$ at $37^{\circ} \mathrm{C}$. Subsequently, $10 \mu \mathrm{l}$ MTT (Sigma-Aldrich; Merck KGaA) was added and incubated for $4 \mathrm{~h}$ at $37^{\circ} \mathrm{C}$. The supernatant was then replaced with $100 \mu \mathrm{l}$ DMSO (Sigma-Aldrich; Merck KGaA) and absorbance was detected at $490 \mathrm{~nm}$ using a multiwell microplate reader (BioTek Instruments, Inc., Winooski, VT, USA).

Colony formation assay. Mia PaCa- 2 and Panc-1 cells were digested, counted and seeded into 6-well plates at a density of 800 cells/well. After adherence overnight, pancreatic cancer cells were treated with BA $(50 \mu \mathrm{M})$, gemcitabine $(5 \mu \mathrm{M})$, or gemcitabine $(5 \mu \mathrm{M})$ combined with BA $(50 \mu \mathrm{M})$ for $24 \mathrm{~h}$ at $37^{\circ} \mathrm{C}$, after which the medium was replaced with drug-free medium containing $10 \%$ FBS. The cells were then allowed to grow for 2 weeks to form colonies. After 2 weeks, the colonies were washed with PBS, fixed with $4 \%$ paraformaldehyde for $30 \mathrm{~min}$ at room temperature and stained for $10 \mathrm{~min}$ at room temperature with $0.1 \%$ crystal violet solution, followed by rinsing and imaging. The number of colonies with a diameter $>0.5 \mathrm{~mm}$ was counted under a microscope (Nikon Eclipse Ti-S; Nikon Corporation, Tokyo, Japan).

Apoptosis assay. The apoptosis of pancreatic cancer cells was assessed using flow cytometry with an Annexin V-fluorescein isothiocyanate (FITC)/7-aminoactinomycin D (7-AAD) apoptosis detection kit (BD Biosciences, Franklin Lakes, NJ, USA), according to the manufacturer's protocol. The preprocessing of pancreatic cancer cells was performed as previously described (36). Cells treated with gemcitabine $(5 \mu \mathrm{M})$, BA $(50 \mu \mathrm{M})$, or gemcitabine $(5 \mu \mathrm{M})$ combined with BA $(50 \mu \mathrm{M})$ for $24 \mathrm{~h}$ at $37^{\circ} \mathrm{C}$ were washed twice in cold PBS and resuspended in $1 \mathrm{X}$ binding buffer (BD Biosciences) at a density of $1 \times 10^{6}$ cells $/ \mathrm{ml}$. Cell suspensions $\left(2.5 \times 10^{5}\right.$ cells $)$ were added to $1.5 \mathrm{ml}$ Eppendorf tubes, to which $5 \mu \mathrm{l}$ allophycocyanin Annexin V and 7-AAD were added, and were gently vortexed. Subsequently, cells were incubated at room temperature for $15 \mathrm{~min}$ in the dark, and the percentage of apoptotic cells was quantified by flow cytometry using a FACSCalibur flow cytometer (BD Biosciences). Data were analyzed using Winmdi2.9 software (The Scripps Research Institute, San Diego, CA, USA). The total apoptotic rate was assessed by adding the rate of Annexin V-FITC ${ }^{+} / 7-\mathrm{AAD}^{-}$cells (early apoptotic cells) and Annexin V-FITC $/ 7-\mathrm{AAD}^{+}$cells (late apoptotic cells) together.

Tumorsphere formation assay. Following treatment with BA $(50 \mu \mathrm{M})$ or AICAR $(2 \mathrm{mM})$, or with BA $(50 \mu \mathrm{M})$ combined with siRNA to knockdown AMPK or siControl for $24 \mathrm{~h}$ at $37^{\circ} \mathrm{C}$, pancreatic cancer cells were digested, counted and seeded in 6-well ultra-low attachment plates (Corning Incorporated, Corning, NY, USA) at a density of 5,000 cells/well in serum-free DMEM/F12 medium (Gibco; Thermo Fisher Scientific, Inc.) containing $20 \mathrm{ng} / \mathrm{ml}$ human FGF, $20 \mathrm{ng} / \mathrm{ml}$ human EGF and 1\% B27 (Gibco; Thermo Fisher Scientific, Inc.). Cells were subsequently cultured at $37^{\circ} \mathrm{C}$ in an atmosphere containing $5 \% \mathrm{CO}_{2}$ for 1 week to form tumorspheres. After 1 week, tumorsphere formation was counted and recorded under a light microscope (Nikon Corporation) at a magnification of $\times 200$.

Wound-scratch assay. The wound-scratch assay was conducted to examine the migratory capacity of pancreatic cancer cells. Briefly, once Mia PaCa-2 and Panc-1 cells were cultured to 90-100\% confluence, a $10-\mu 1$ pipette tip was used to generate a wound in the surface of the cells in a 6-well plate, and then the cells were treated with or without BA $(50 \mu \mathrm{M})$ for $48 \mathrm{~h}$ at $37^{\circ} \mathrm{C}$. Images of the same fields at the indicated time-points $(0$ and $48 \mathrm{~h}$ ) were captured under a light microscope (Nikon Corporation) at a magnification of $\mathrm{x} 100$.

Transwell invasion assay. Transwell chamber (EMD Millipore, Billerica, MA, USA) assays were performed to assess the invasive ability of pancreatic cancer cells, in accordance with a previously described protocol (37). Briefly, Mia PaCa-2 and Panc-1 cells were serum-starved for 6-8 $\mathrm{h}$ and were pretreated with BA $(50 \mu \mathrm{M})$ or $\operatorname{AICAR}(2 \mathrm{mM})$ for $24 \mathrm{~h}$ at $37^{\circ} \mathrm{C}$. In addition, the upper chamber was coated with Matrigel (Sigma-Aldrich; Merck KGaA) and was incubated at $37^{\circ} \mathrm{C}$ in an atmosphere containing $5 \% \mathrm{CO}_{2}$ for $5 \mathrm{~h}$. Subsequently, Mia PaCa-2 and Panc-1 cells $\left(1 \times 10^{5}\right)$ were digested, resuspended in serum-free medium and seeded into the upper chamber. The pancreatic cancer cells were allowed to invade into the lower chamber, which contained medium supplemented with $10 \%$ FBS, for $24 \mathrm{~h}$ at $37^{\circ} \mathrm{C}$. The non-invading cells on the upper side were scraped off using a cotton swab, and the membrane was then fixed with $4 \%$ paraformaldehyde for $30 \mathrm{~min}$ at room temperature and stained for $10 \mathrm{~min}$ at room temperature with $0.1 \%$ crystal violet. Subsequently, the number of cells on each membrane was counted in 10 random fields and images were captured under a light microscope (Nikon Corporation) at $\times 200$ magnification. The values reported are the mean of triplicate experiments.

Reverse transcription-quantitative polymerase chain reaction $(R T-q P C R)$. Following treatment with or without BA $(50 \mu \mathrm{M})$, with various concentrations of gemcitabine $(0,1$ and $5 \mu \mathrm{M})$, or with gemcitabine $(5 \mu \mathrm{M})$ combined with BA $(50 \mu \mathrm{M})$ for $24 \mathrm{~h}$ at $37^{\circ} \mathrm{C}$, total RNA was extracted from the cells using TRIzol reagent (Invitrogen; Thermo Fisher Scientific, Inc.), according to the manufacturer's protocol. The isolated total RNA was then reverse transcribed into cDNA using a PrimeScript RT reagent kit (Takara Biotechnology Co., Ltd., Dalian, China), according to the manufacturer's protocol. An iQ5 Multicolor Real-Time PCR Detection system (Bio-Rad Laboratories, Inc., Hercules, CA, USA) and a SYBR Green PCR kit (Takara Biotechnology Co., Ltd.) were used to conduct RT-qPCR, according to the manufacturers' protocols. The RT-qPCR 
experimental steps were conducted as previously described (38). The specificity of the amplified PCR products was evaluated by melting curve analysis, and the comparative $\mathrm{Cq}$ method was used to determine the expression levels of each target gene, with GAPDH as a normalization control, as previously described (39). The primer sequences used for RT-qPCR were as follows: Sox-2, forward 5'-GCCGAGTGGAAACTT TTGTCG-3',reverse 5'-GGCAGCGTGTACTTATCCTTCT-3'; Nanog, forward 5'-TTTGTGGGCCTGAATAAGCAG-3', reverse 5'-AGGGCTGTCCTGAATAAGCAG-3'; Oct4, forward 5'-CTGGGTTGATCCTCGGACCT-3', reverse 5'-CCATCGG AGTTGCTCTCCA-3'; CD133, forward 5'-TACAACGCCAA ACCACGACTGT-3', reverse 5'-TCTGAACCAATGGAATTC AAGACCCTTT-3'; ALDH1, forward 5'-TGTTAGCTGATGC CGACTTG-3', reverse 5'-CTTCTTAGCCCGCTCAACAC-3'; EpCAM, forward 5'-ATGTTTGGT GATGAAGGCAGAA-3', reverse 5'-ATCGCAGT CAGGATCATAAAGC-3'; and $\beta$-actin, forward 5'-ATCGTGCGTGACATTAAGGAGAAG-3' and reverse 5'-AGGAAGAAGGCTGGAAGAGTG-3'.

Immunofluorescence staining. Following treatment with or without BA $(50 \mu \mathrm{M})$ for $24 \mathrm{~h}$ at $37^{\circ} \mathrm{C}$, pancreatic cancer cells $\left(1 \times 10^{6}\right)$ were washed with PBS and fixed in $4 \%$ paraformaldehyde for $30 \mathrm{~min}$ at room temperature. Fixed cells were washed again with PBS and permeabilized in $0.5 \%$ Triton X-100 diluted in PBS for $10 \mathrm{~min}$; cells on the slides were subsequently blocked with $5 \%$ bovine serum albumin (Beyotime Institute of Biotechnology, Guangzhou, China) for $1 \mathrm{~h}$ at room temperature and were then incubated with a Sox 2 antibody (1:150 dilution) at $4^{\circ} \mathrm{C}$ overnight. Following incubation with a secondary antibody (1:150 dilution; cat. no. 913921; Jackson ImmunoResearch Laboratories, Inc., West Grove, PA, USA) for $1 \mathrm{~h}$ at room temperature, the nuclei of the cells were stained with DAPI and the cells were sealed on glass slides. A confocal microscope (Zeiss AG, Oberkochen, Germany) was used to capture images and record the cells at a wavelength of $488 \mathrm{~nm}$ and a magnification of $\mathrm{x} 400$.

Western blotting. Following treatment with various concentrations of BA $(0,25$ and $50 \mu \mathrm{M})$, with $\mathrm{BA}(50 \mu \mathrm{M})$ for various durations $(0,5,15,30,60$ and $120 \mathrm{~min})$, various concentrations of AICAR ( 0 and $2 \mathrm{mM}$ ), various concentrations of gemcitabine $(0,1$ and $5 \mu \mathrm{M})$, or with BA $(50 \mu \mathrm{M})$ combined with siRNA to knockdown AMPK or siControl, or with gemcitabine $(5 \mu \mathrm{M})$ combined with BA $(50 \mu \mathrm{M})$ for $24 \mathrm{~h}$ at $37^{\circ} \mathrm{C}$, total proteins were extracted from $\mathrm{Mia} \mathrm{PaCa}-2$ and Panc-1 cells $\left(1 \times 10^{6}\right)$ grown under experimental conditions using radioimmunoprecipitation assay lysis buffer (Beyotime Institute of Biotechnology). The bicinchoninic acid protein assay kit (Pierce; Thermo Fisher Scientific, Inc.) was used to determine protein concentrations, according to the manufacturer's protocol. Western blotting was conducted as previously described (40). Briefly, proteins $(150 \mu \mathrm{g})$ were separated by $10 \%$ SDS-PAGE and were transferred onto polyvinylidene difluoride membranes. Subsequently, the membranes were blocked with $5 \%$ non-fat dry milk in Tris-buffered saline containing $0.1 \%$ Tween (TBST) and were incubated with primary antibodies overnight at $4^{\circ} \mathrm{C}$. After three washes in TBST (10 min/wash), the membranes were incubated with goat anti-rabbit immunoglobulin $\mathrm{G}$ ( $\mathrm{IgG}$ )-horseradish peroxidase
(HRP) (1:10,000 dilution; cat. no. ab6721; Abcam) or goat anti-mouse IgG-HRP (1:10,000 dilution; cat. no. ab6789; Abcam) secondary antibodies for $1 \mathrm{~h}$ at room temperature, and were washed again. The immunoreactive bands were visualized using a chemiluminescence detection system (EMD Millipore) through the peroxidase reaction, and images of the bands were recorded using the ChemiDoc XRS imaging system (Bio-Rad Laboratories, Inc.). $\beta$-actin was used as an internal loading control.

Immunohistochemical analysis. The present study was approved by the Ethical Committee of The First Affiliated Hospital of Xi'an Jiaotong University (Xi'an, China), and written informed consent was obtained from the patients. A total of 72 pancreatic cancer tissues and eight normal pancreatic samples were collected from the Department of Hepatobiliary Surgery, The First Affiliated Hospital of Xi'an Jiaotong University. The details of these samples were provided in our previous study (41). The tissue samples were fixed in $10 \%$ paraformaldehyde and were embedded in paraffin for further immunohistochemical analysis, as previously described (42). Briefly, pancreatic tissues were cut into $5-\mu \mathrm{m}$ sections on glass slides, and the sections were deparaffinized and rehydrated, after which, the sections underwent antigen retrieval and endogenous enzyme blocking. The sections were then incubated with primary antibodies (anti-P-AMPK and anti-Sox 2; 1:150 dilution) overnight at $4^{\circ} \mathrm{C}$, followed by incubation with streptavidin peroxidase (Dako LSAB + HRP kit; Dako; Agilent Technologies, Inc., Santa Clara, CA, USA) for $30 \mathrm{~min}$ at room temperature. The sections were incubated with DAB for $5 \mathrm{~min}$ followed by counterstaining with hematoxylin for $2 \mathrm{~min}$ at room temperature. Finally, the sections were observed under a light microscope (Nikon Corporation).

Gene silencing by small interfering (si)RNA. Loss-of-function analysis was conducted using siRNA to knockdown AMPK, which was purchased from Shanghai GenePharma Co., Ltd. (Shanghai, China). The sequences of siRNA and corresponding siControl are provided in our previous study (41). Each siRNA (100 nM) was mixed with Lipofectamine ${ }^{\circledR} 2000$ (Invitrogen; Thermo Fisher Scientific, Inc.) as a carrier and were transfected into pancreatic cancer cells $\left(1 \times 10^{6}\right)$ for $10 \mathrm{~h}$ at $37^{\circ} \mathrm{C}$, according to the manufacturer's protocol. The efficacy of AMPK knockdown was validated by western blot analysis. A total of $48 \mathrm{~h}$ post-transfection, these cells underwent further experimentation (Transwell invasion assay and tumorsphere formation assay).

Statistical analysis. Data shown are representative of three independent experiments, and for each experiment, at least three samples were analyzed for each treatment group. Data are presented as the means \pm standard deviation. Differences were evaluated using Student's t-test, or one-way analysis of variance for multiple comparisons with the Student-Newman-Keuls method as a post hoc test. Statistical analysis of the human tissue data was performed using Pearson's $\chi^{2}$ test. All statistical analyses were performed using SPSS 20.0 (SPSS, Inc., Chicago, IL, USA). $\mathrm{P}<0.05$ was considered to indicate a statistically significant difference. 
A

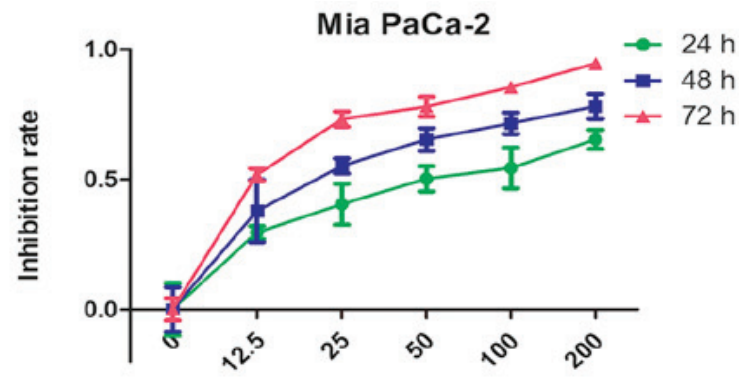

Betulinic acid concentration $(\mu \mathrm{M})$

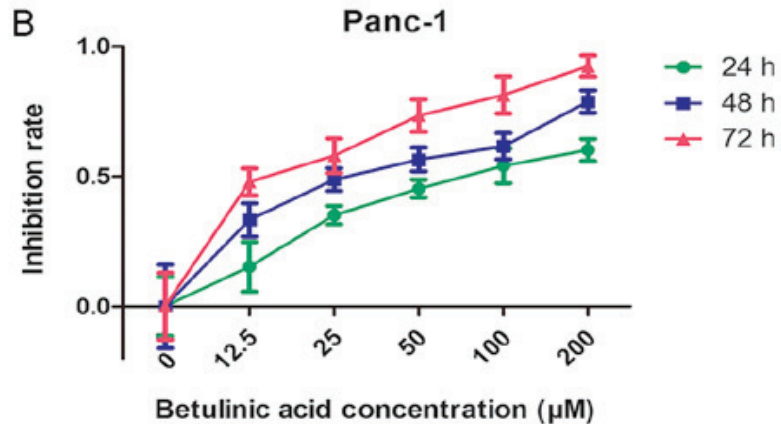

Panc-1
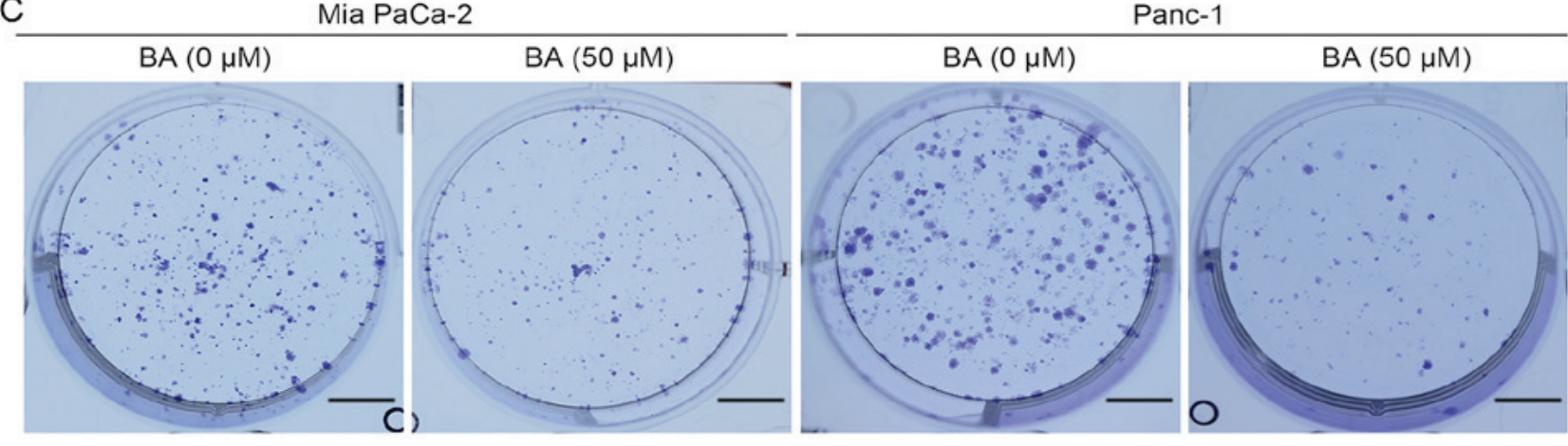

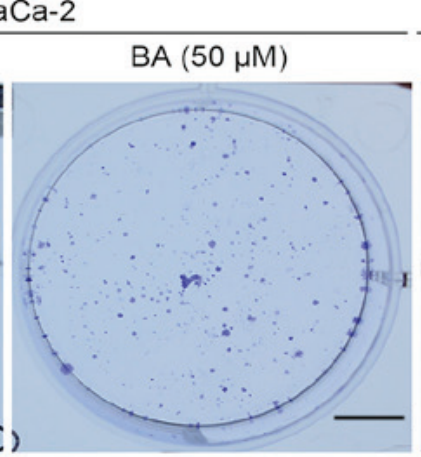

Mia PaCa-2
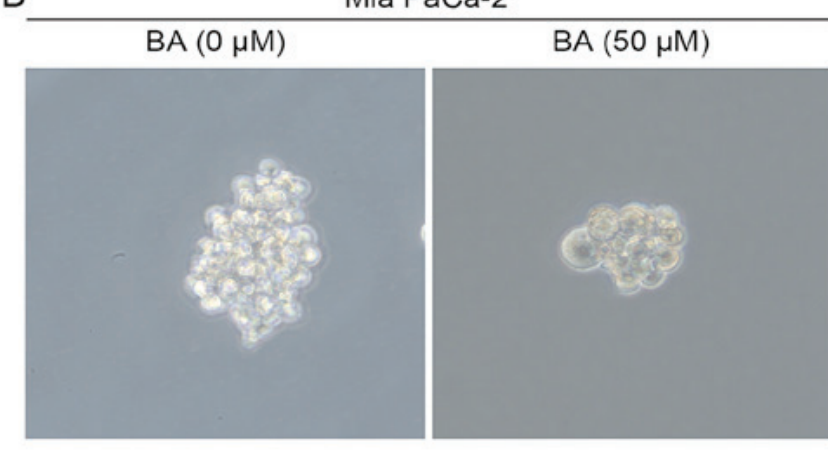

E

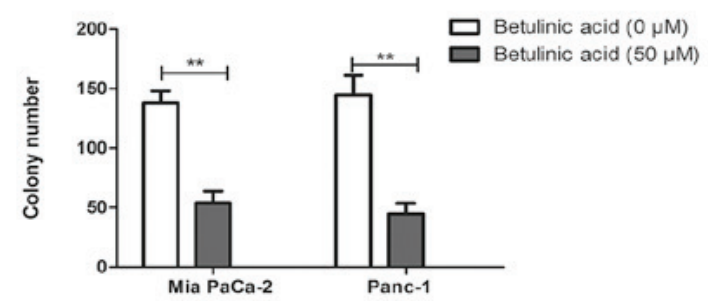

\section{$\mathrm{F}$}

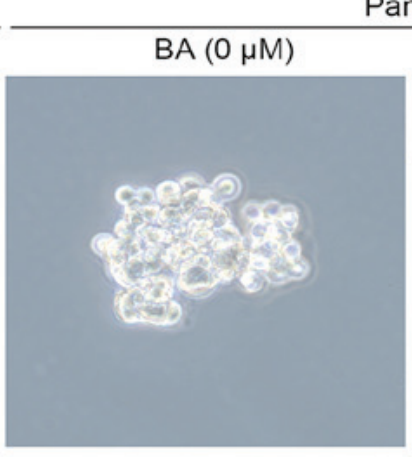

Panc-1

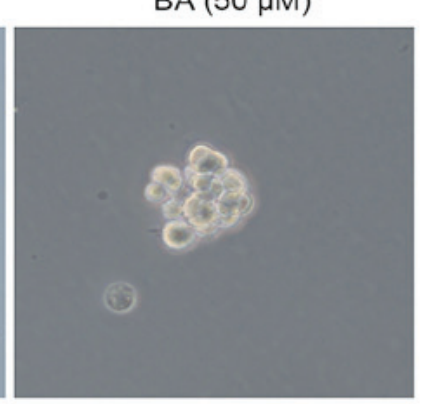

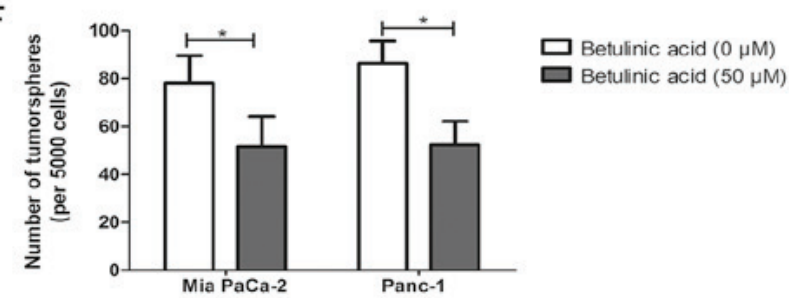

Figure 1. Effects of BA on the proliferation and tumorsphere formation of pancreatic cancer cells. (A and B) Mia PaCa-2 and Panc-1 cells were incubated with a series of BA concentrations (0, 12.5, 25, 50, 100 and $200 \mu \mathrm{M})$ for 24, 48 and $72 \mathrm{~h}$, and cell viability was evaluated by MTT assay. (C and E) Effects of $\mathrm{BA}$ on the colony-forming ability of Mia PaCa-2 and Panc-1 cells were assessed by colony formation assay. Images are representative of three independent experiments, and the colony number was counted and plotted. Scale bar, $1 \mathrm{~cm}$. (D and F) Tumorsphere formation assay of Mia PaCa- 2 and Panc-1 cells treated with or without $50 \mu \mathrm{M}$ BA. The number of tumorspheres was counted and plotted. Magnification, $\mathrm{x} 200 .{ }^{*} \mathrm{P}<0.05$, ${ }^{* *} \mathrm{P}<0.01$. $\mathrm{BA}$, betulinic acid.

\section{Results}

$B A$ inhibits the proliferation and tumorsphere formation of pancreatic cancer cells. To determine whether BA could suppress the viability of pancreatic cancer cells, the MTT assay was used. Briefly, Mia PaCa-2 and Panc-1 cells were treated with a series of gradually increasing concentrations of BA [0 (control), 12.5, 25, 50, 100 and $200 \mu \mathrm{M}]$ for 24,48 and $72 \mathrm{~h}$, and absorbance was measured at $490 \mathrm{~nm}$ at the designated time-points to analyze cell viability. The results indicated that
BA impaired the growth of Mia PaCa- 2 and Panc- 1 cells in timeand dose-dependent manners (Fig. 1A and B). The half maximal inhibitory concentration of BA was $\sim 50 \mu \mathrm{M}$ for both Panc-1 and Mia PaCa- 2 cells, and it exerted no cytotoxic effects on a pancreatic duct epithelial cell line (data not shown). This concentration of BA was in accordance with previously used dosages (34); therefore, $50 \mu \mathrm{M}$ BA was used for subsequent experiments. The present study subsequently examined the effects of BA on colony formation and tumorsphere formation in $\mathrm{Mia} \mathrm{PaCa}-2$ and Panc-1 cells (Fig. 1C-F). As shown in Fig. 1C and E, compared 
A

A $\quad$ Mia PaCa-2

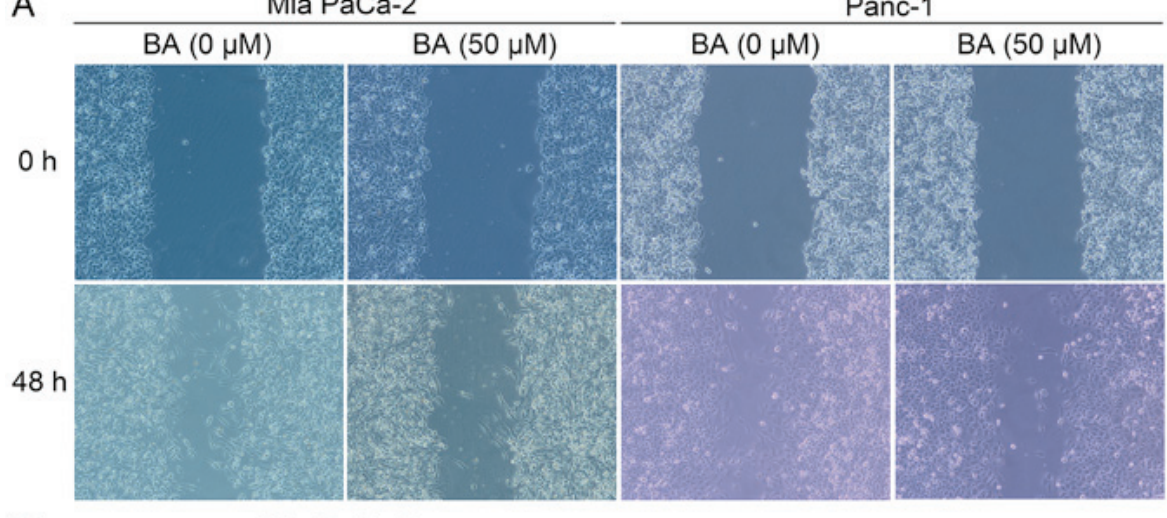

B

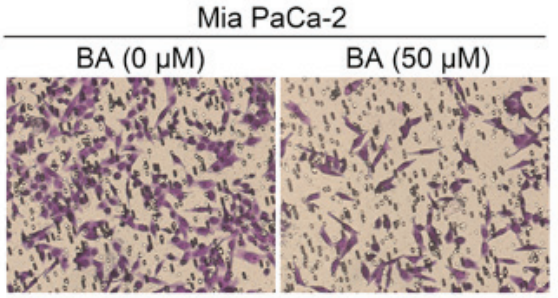

C
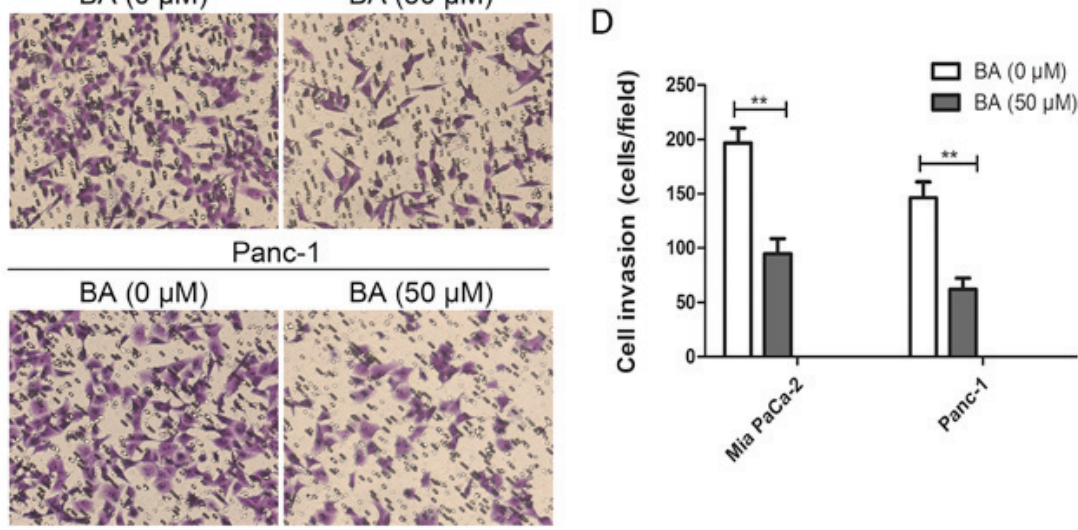

$\mathrm{E}$
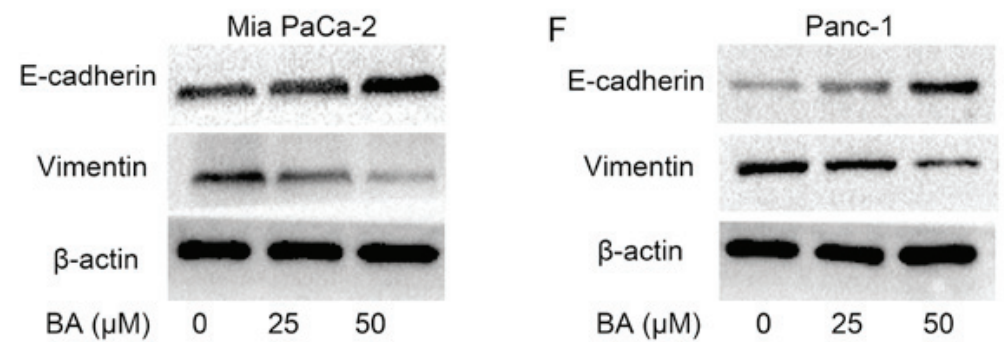

Figure 2. Effects of BA on the migration and invasion of pancreatic cancer cells. (A) Wound-scratch assays were conducted on Mia PaCa-2 and Panc-1 cells pretreated with or without $50 \mu \mathrm{M}$ BA. Images were visualized at 0 and $48 \mathrm{~h}$. Magnification, x100. (B-D) Effects of BA on the invasive ability of Mia PaCa-2 and Panc-1 cells were evaluated by Matrigel invasion assay. Images are representative of three independent experiments, and the invasive cells were counted and plotted. Magnification, x200. ${ }^{* *} \mathrm{P}<0.01$. (E and F) Mia PaCa-2 and Panc-1 cells were pretreated with BA $(0,25$ and $50 \mu \mathrm{M})$ for $48 \mathrm{~h}$, and western blot analysis was performed to assess the expression of epithelial-mesenchymal transition markers (E-cadherin and vimentin). BA, betulinic acid.

with in untreated control cells, the number of colonies in cells treated with $50 \mu \mathrm{M}$ BA was markedly decreased. Since cancer stemness is associated with mechanisms underlying cancer metastasis and occurrence, the present study further explored the role of BA in the stemness of pancreatic cancer. As shown in Fig. 1D and F, tumorsphere formation was decreased in Mia PaCa-2 and Panc-1 cells upon BA treatment compared with in untreated cancer cells.

$B A$ suppresses the migration and invasion of pancreatic cancer cells via inhibiting EMT. It has previously been reported that the EMT process endows cancer cells with an increased self-renewal capability and mesenchymal phenotype, which is necessary for tumor metastasis (43). Therefore the present study examined the effects of BA on EMT, migration and invasion of pancreatic cancer cells. Notably, BA-treated Mia PaCa-2 and Panc-1 cells exhibited reduced migration and invasion in vitro compared with untreated cells (Fig. 2A-D). In addition, the results of western blotting suggested that the epithelial marker E-cadherin was elevated, whereas the mesenchymal marker vimentin was decreased in BA-treated Mia PaCa-2 and Panc-1 cells compared with the control (Fig. 2E and F). Collectively, these data indicated that BA may inhibit the migration and invasion of pancreatic cancer cells through targeting EMT.

$B A$ inhibits the stemness of pancreatic cancer cells and activates AMPK signaling. Although the number of known molecular markers of the cancer stem-like phenotype is still increasing, three transcription factors; namely Sox 2, Oct4 and Nanog, have been strongly validated as master regulators in the maintenance of the cancer stem-like phenotype (8). The present study examined whether BA treatment affects the expression of these master mediators of pluripotency 


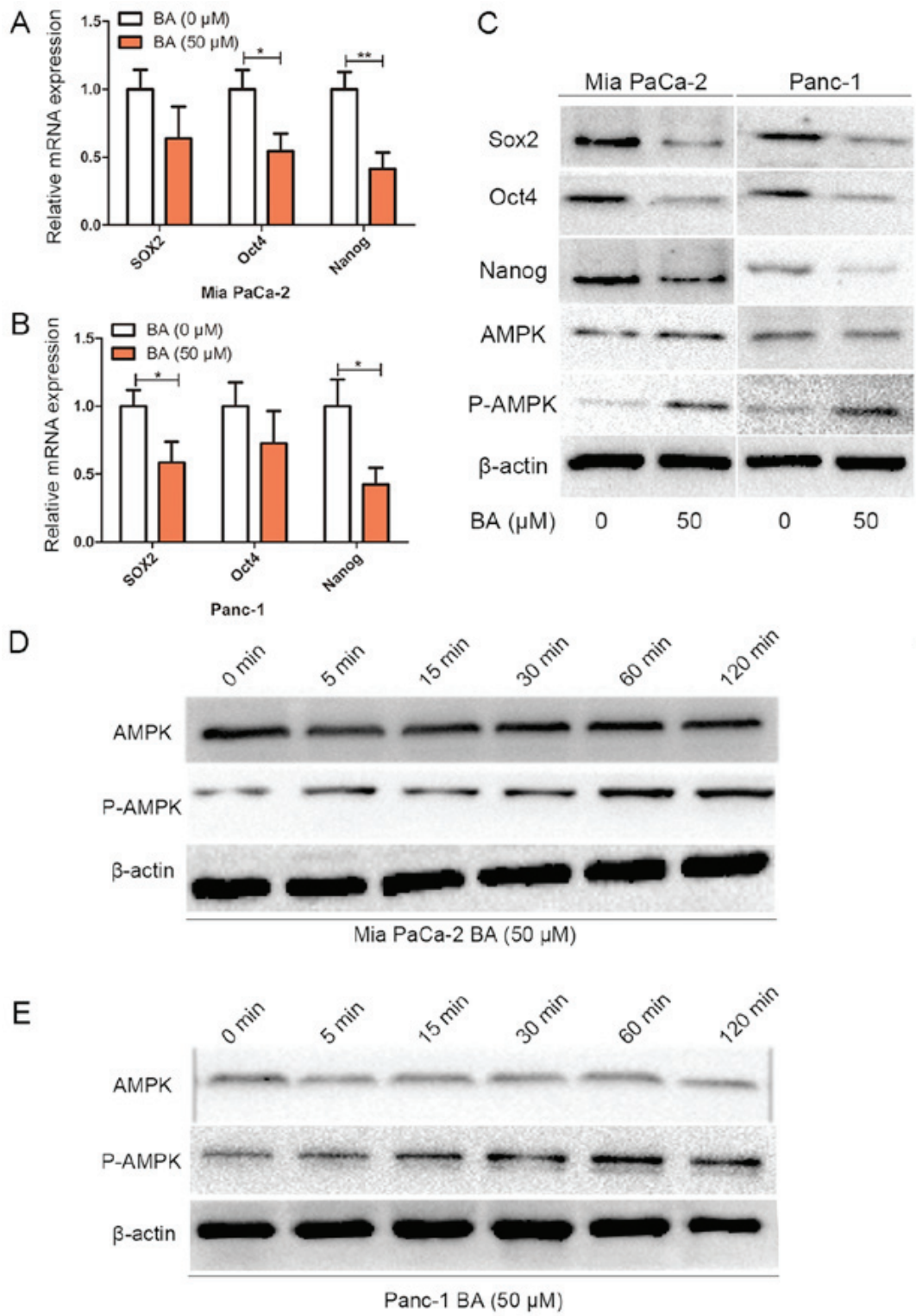

$\mathrm{F}$

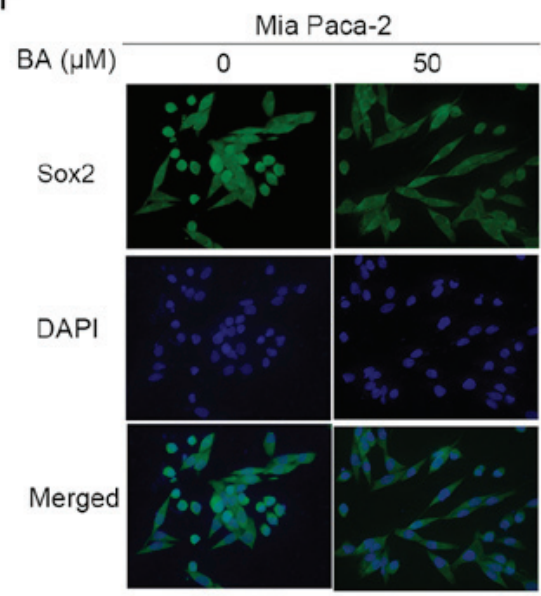

G

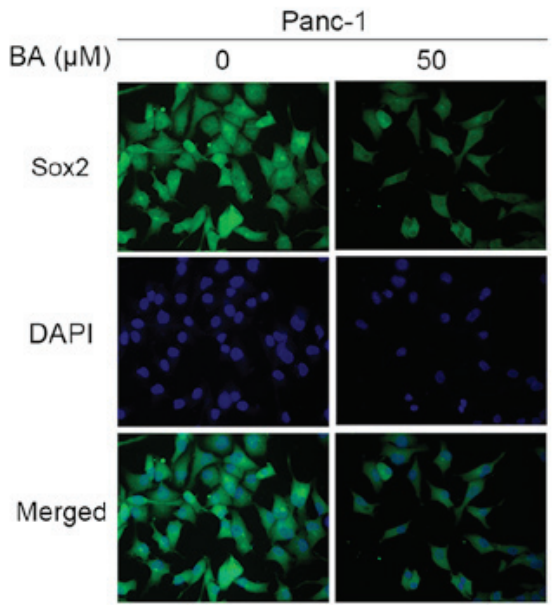

Figure 3. BA inhibits the stemness of pancreatic cancer cells and activates AMPK signaling. (A and B) Mia PaCa-2 and Panc-1 cells were pretreated with BA for $24 \mathrm{~h}$, total RNA was extracted and reverse transcription-quantitative polymerase chain reaction was conducted to detect the expression levels of Sox 2 , Oct4 and Nanog. ${ }^{*} \mathrm{P}<0.05$ and ${ }^{* *} \mathrm{P}<0.01$. (C) Mia PaCa-2 and Panc-1 cells were pretreated with or without $50 \mu \mathrm{M}$ BA for 48 h, and western blot analysis was performed to assess the protein expression levels of master pluripotency regulators (Sox2, Oct4 and Nanog), total AMPK and P-AMPK. (D and E) Mia PaCa-2 and Panc-1 cells were treated with $50 \mu \mathrm{M}$ BA at various time-points $(0,5,15,30,60$ and $120 \mathrm{~min})$, and total protein was extracted to detect the expression levels of P-AMPK by western blotting. (F and G) Mia PaCa-2 and Panc-1 cells were pretreated with BA for $24 \mathrm{~h}$, and immunofluorescence analysis was conducted to assess the expression and nuclear localization of Sox 2 in Mia PaCa-2 and Panc-1 cells. Magnification, x400. AMPK, 5' adenosine monophosphate-activated protein kinase; BA, betulinic acid; Oct4, octamer-binding protein 4; P, phosphorylated; Sox2, SRY-box 2.

(Fig. 3). RT-qPCR analysis revealed that BA treatment suppressed the mRNA expression levels of Sox2, Oct4 and Nanog (Fig. 3A and B). In addition, as shown in Fig. 3C, western blotting indicated that compared with the group without BA treatment, treatment of Mia PaCa-2 and Panc-1 cells with $50 \mu \mathrm{M}$ BA downregulated the expression levels of Sox2, Oct4 and Nanog, and upregulated P-AMPK expression. The suppressive effects of BA on other stemness markers (CD133, ALDH1 and EpCAM) were similar to those on the aforementioned three master regulators (data not shown). The findings of immunofluorescence analysis also confirmed that BA could suppress the expression and nuclear localization of Sox 2 in both pancreatic cancer cell lines (Fig. 3F and G). Notably, AMPK signaling has an important influence on the cancer stem-like phenotype $(20,44)$. Therefore, to investigate whether BA could activate AMPK signaling, Mia PaCa-2 and Panc-1 cells were treated with BA at various time-points $(0$, $15,30,60,90$ and $120 \mathrm{~min}$ ), and total protein was extracted a to detect the expression levels of P-AMPK by western blotting. The results revealed that BA treatment enhanced the expression of P-AMPK in a time-dependent manner (Fig. 3D and E). Collectively, these data indicated that BA treatment downregulated the expression of Sox2, Oct4 and Nanog, and activated AMPK signaling in pancreatic cancer cells.

AMPK activation by AICAR exhibits similar effects to $B A$ on EMT and stemness of pancreatic cancer cells. To uncover the potential association between AMPK signaling 
A

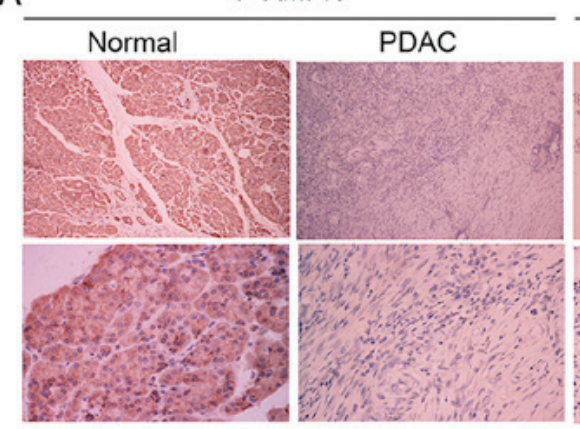

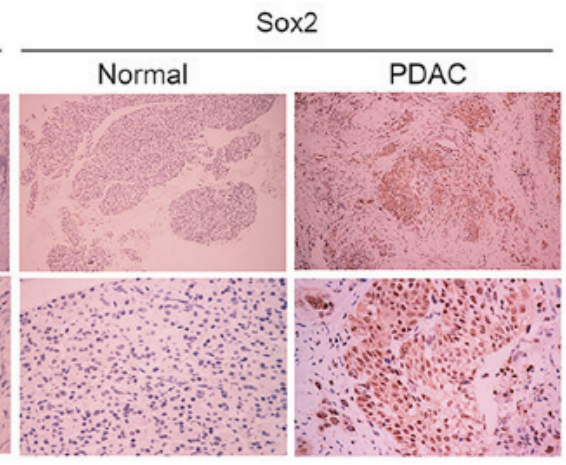

C

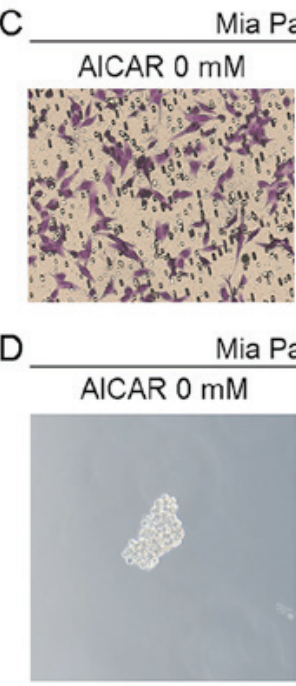

E

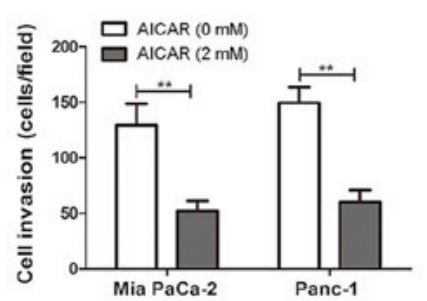

Panc-1
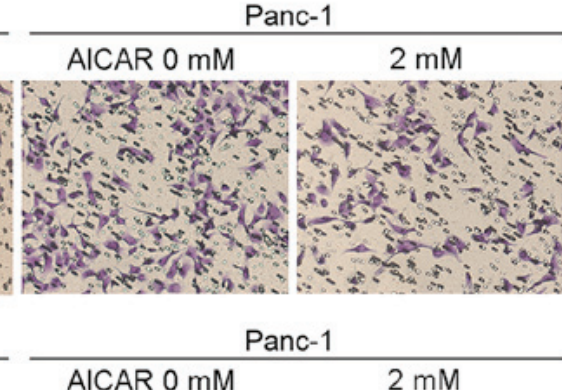

B

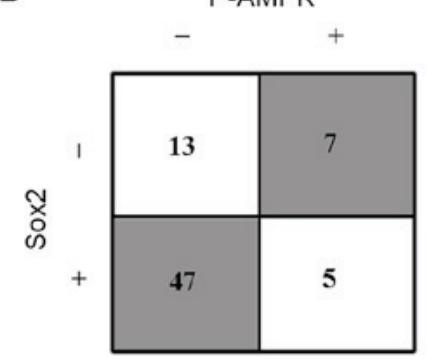

G

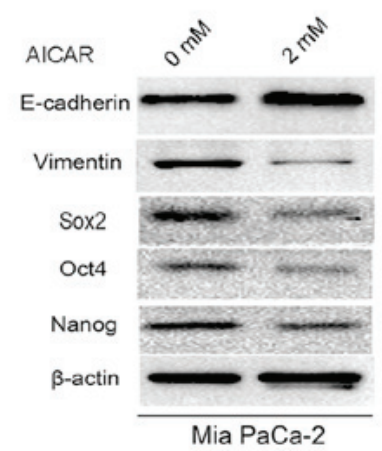

$\mathrm{H}$

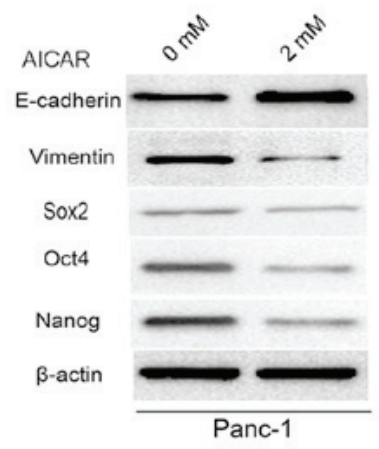

Figure 4. AMPK activation by AICAR exerts similar effects to betulinic acid on EMT and stemness of pancreatic cancer cells. (A) Representative images of immunohistochemical staining of P-AMPK and SOX2 in normal pancreatic tissues and pancreatic cancer tissues. Magnification, $\mathrm{x} 100$ for the upper images and $\mathrm{x} 400$ for the lower images. (B) An inverse association between P-AMPK and SOX 2 expression was detected in pancreatic cancer tissues. P $<0.05$ by two-tailed $\chi^{2}$ test. ( $C$ and E) Effects of AMPK activation by AICAR $(2 \mathrm{mM})$ on the invasive ability of Mia PaCa- 2 and Panc- 1 cells were evaluated by Matrigel invasion assay. Images are representative of three independent experiments, and the invasive cells were counted and plotted. Magnification, $\mathrm{x} 200$. ${ }^{* *} \mathrm{P}<0.01$. ( $\mathrm{D}$ and F) Tumorsphere formation assay of Mia PaCa-2 and Panc-1 cells treated with or without 2 mM AICAR. The number of tumorspheres was counted and plotted. Magnification, $\mathrm{x} 200{ }^{* * *} \mathrm{P}<0.01$. ( $\mathrm{G}$ and $\mathrm{H}$ ) Mia PaCa-2 and Panc-1 cells were pretreated with or without 2 mM AICAR for $48 \mathrm{~h}$, and western blot analysis was performed to assess the expression levels of master pluripotency regulators (Sox2, Oct4, and Nanog) and EMT markers (E-cadherin and vimentin). AICAR, 5-aminoimidazole-4-carboxamide 1- $\beta$-D-ribofuranoside; AMPK, 5 ' adenosine monophosphate-activated protein kinase; EMT, epithelial-mesenchymal transition; Oct4, octamer-binding protein 4; P, phosphorylated; PDAC, pancreatic ductal adenocarcinoma; Sox2, SRY-box 2.

and cancer stemness, immunohistochemical analysis was conducted to detect the expression levels of P-AMPK and Sox 2 in normal pancreatic tissues and pancreatic cancer tissues. Immunohistochemical analysis revealed that, compared with in normal pancreatic tissues, the expression levels of P-AMPK were decreased in pancreatic cancer tissues. Conversely, the expression levels of Sox 2 were markedly elevated (Fig. 4A). Furthermore, Sox 2 expression was detected in $78.3 \%$ (47/60) of pancreatic cancer tissues with negative P-AMPK expression (Fig. 4B), thus suggesting an inverse relationship between P-AMPK signaling and the cancer stem-like phenotype, and indicating that downregulation of P-AMPK may lead to increased cancer stemness.
In order to further clarify the effects of AMPK signaling on the maintenance of pancreatic cancer cell stemness and to determine its role in EMT, an AMPK activator, AICAR (2 $\mathrm{mM}$ ), was used to treat $\mathrm{Mia} \mathrm{PaCa}-2$ and Panc-1 cells for $24 \mathrm{~h}$. The results suggested that AMPK activation by AICAR effectively inhibited the invasion and tumorsphere formation of Mia PaCa-2 and Panc-1 cells compared with the vehicle control (Fig. 4C-F). Furthermore, the results of western blotting indicated that the expression levels of the epithelial marker E-cadherin were elevated, whereas those of the mesenchymal marker vimentin were decreased in AICAR-treated Mia PaCa-2 and Panc-1 cells compared with the control. In addition, the expression levels of the 
A

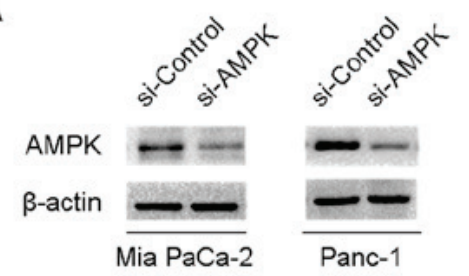

B

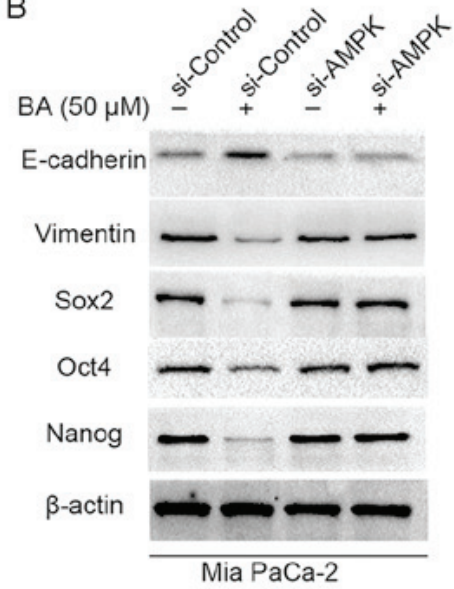

C

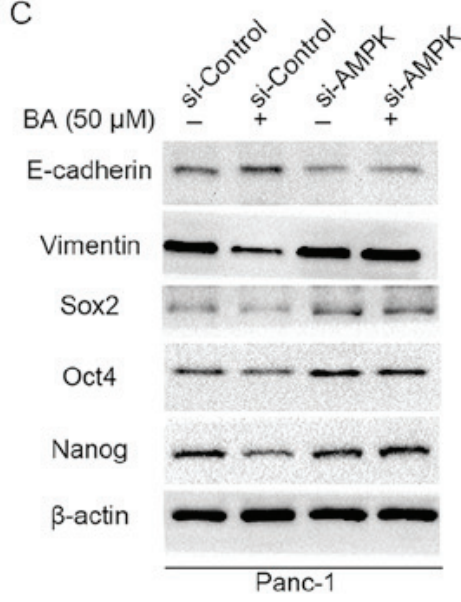

D

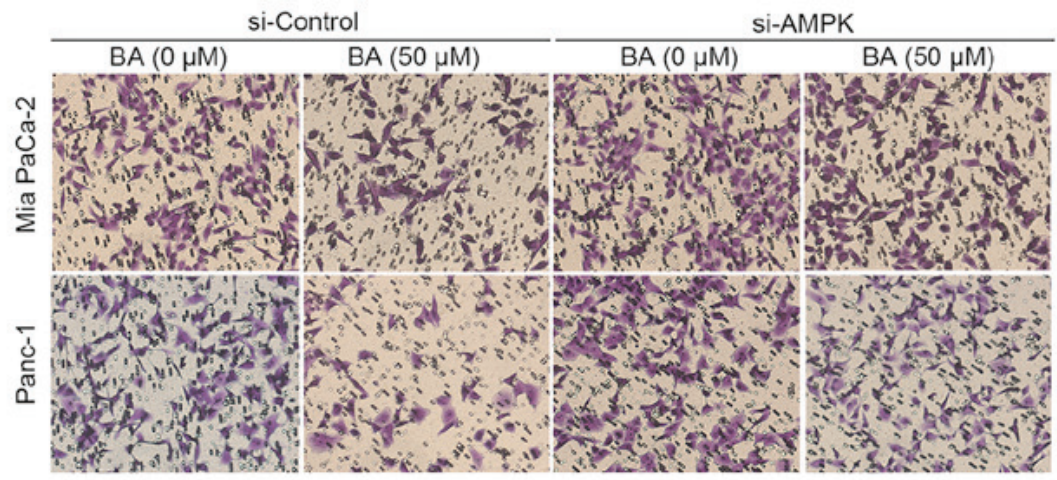

E
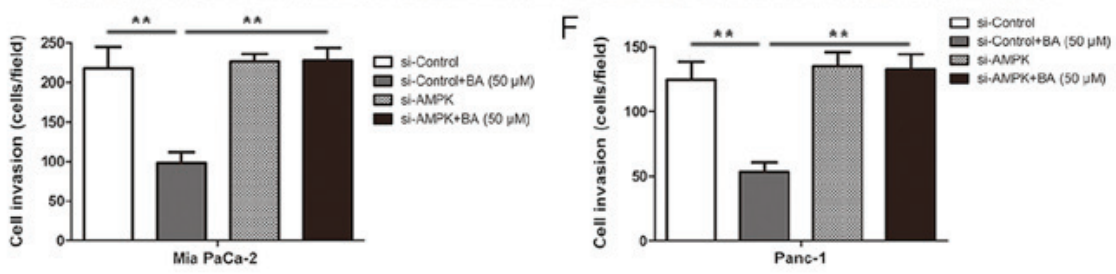

G
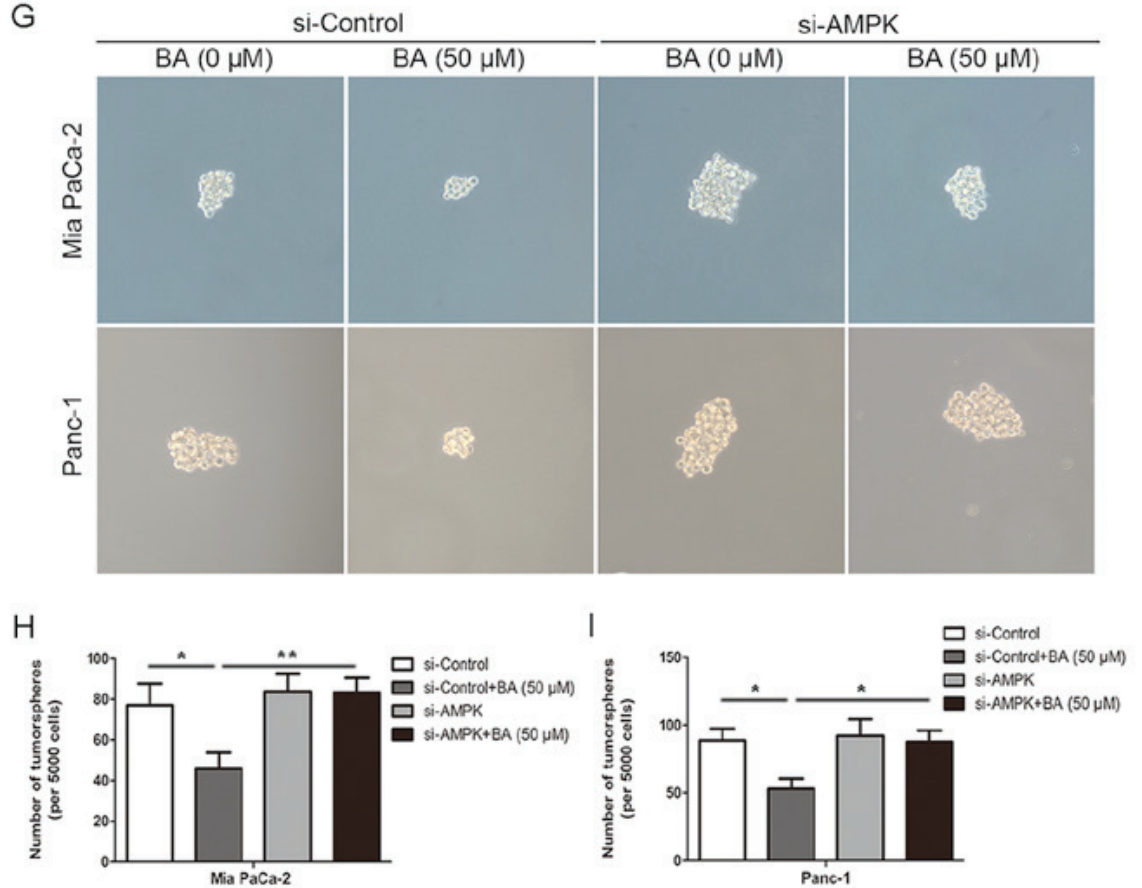

Figure 5. Knockdown of AMPK rescues BA-induced suppression of EMT and stemness in pancreatic cancer cells. (A) Western blotting confirmed the successful silencing of AMPK in Mia PaCa-2 and Panc-1 cells. $\beta$-actin was used as an internal loading control. (B and C) Western blot analysis suggested that silencing AMPK by siRNA reversed BA-induced inhibition of the expression of master pluripotency regulators (Sox2, Oct4 and Nanog) and EMT markers (E-cadherin and vimentin) in Mia PaCa-2 and Panc-1 cells. $\beta$-actin was used as an internal loading control. (D-F) Matrigel invasion assay revealed that silencing AMPK by siRNA reversed BA-induced suppression of the invasion of Mia PaCa-2 and Panc-1 cells. Images are representative of three independent experiments, and the invasive cells were counted and plotted. Magnification, $\mathrm{x} 200{ }^{* *} \mathrm{P}<0.01$. (G-I) Tumorsphere formation assay exhibited that knocking down AMPK by siRNA reversed BA-induced inhibition of tumorsphere formation in Mia PaCa-2 and Panc- 1 cells. The number of tumorspheres was counted and plotted. Magnification, $\mathrm{x} 200 .{ }^{*} \mathrm{P}<0.05,{ }^{* *} \mathrm{P}<0.01$. AMPK, 5 ' adenosine monophosphate-activated protein kinase; BA, betulinic acid; EMT, epithelial-mesenchymal transition; Oct4, octamer-binding protein 4; si/siRNA, small interfering RNA; Sox2, SRY-box 2.

master pluripotency inducers (Sox2, Oct4 and Nanog) were decreased (Fig. 4G and H). Similar effects were observed on other stemness markers (CD133, ALDH1 and EpCAM; data not shown). These data indicated that AMPK activation by AICAR may exert similar effects to BA on EMT and stemness of pancreatic cancer cells.

Knockdown of AMPK rescues BA-induced suppression of EMT and stemness in pancreatic cancer cells. In order to test the hypothesis that BA inhibits stemness and EMT of pancreatic cancer through activating AMPK signaling, AMPK-specific siRNA (si-AMPK) was used to silence AMPK expression in pancreatic cancer cells in conjunction with BA treatment. Successful silencing of AMPK expression was confirmed in Mia PaCa-2 and Panc-1 cells by western blotting (Fig. 5A). Subsequently, AMPK-depleted and control pancreatic cancer cells (Mia PaCa-2-siAMPK, Mia PaCa-2-siControl, Panc-1-siAMPK and Panc-1-siControl) were treated with BA and were subjected to Transwell invasion assay, tumorsphere formation assay and western blot analysis (Fig. 5). BA could 
A
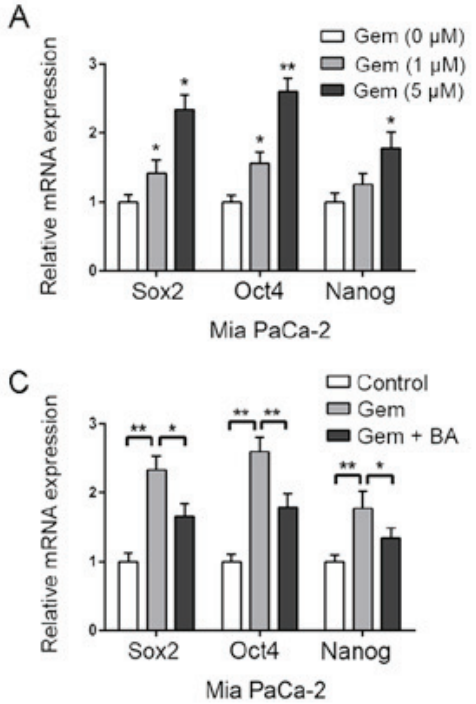

E

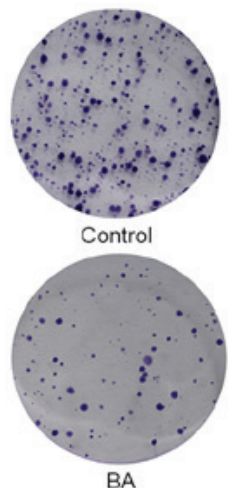

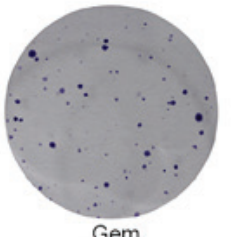

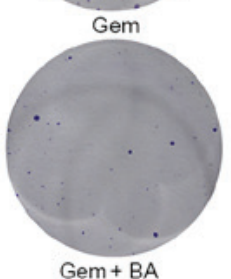

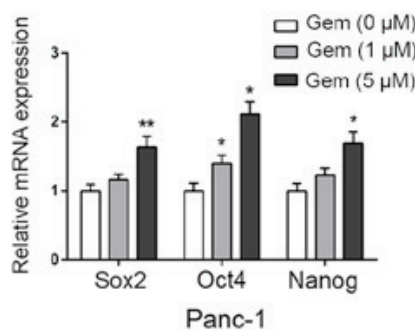

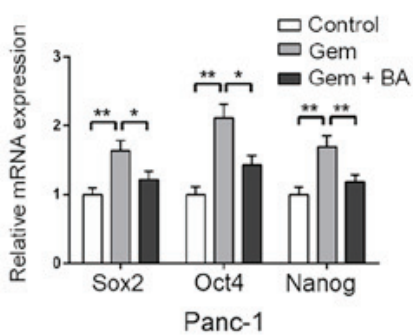

F

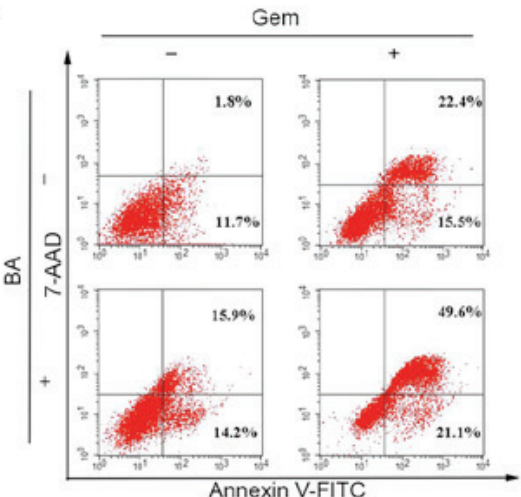

D
B
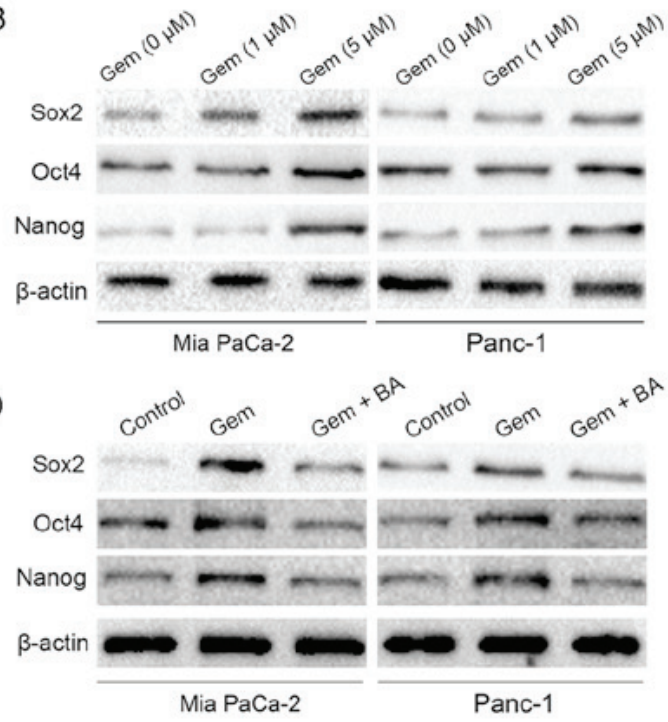

G

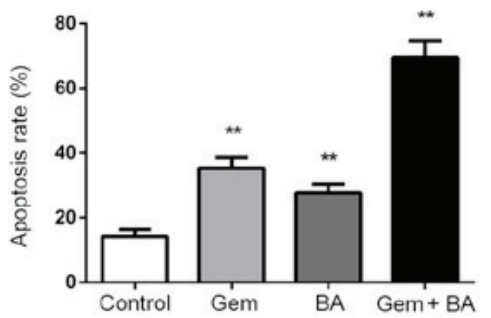

Figure 6. BA reverses gemcitabine-induced stemness and enhances the sensitivity of pancreatic cancer cells to gemcitabine. (A) Mia PaCa-2 and Panc-1 cells were pretreated with various concentrations of gemcitabine $(0,1$ and $5 \mu \mathrm{M})$ for $24 \mathrm{~h}$, total RNA was extracted and RT-qPCR was conducted to detect the expression levels of Sox 2, Oct 4 and Nanog. ${ }^{*} \mathrm{P}<0.05$ and ${ }^{* *} \mathrm{P}<0.01$, compared with the control group. (B) Mia PaCa-2 and Panc-1 cells were pretreated with various concentrations of gemcitabine $(0,1$ and $5 \mu \mathrm{M})$ for $24 \mathrm{~h}$, and western blot analysis was performed to assess the expression levels of master pluripotency regulators (Sox2, Oct4 and Nanog). (C) Effects of BA $(50 \mu \mathrm{M})$ on gemcitabine $(5 \mu \mathrm{M})$ treatment-induced stemness were measured by RT-qPCR analysis. ${ }^{*} \mathrm{P}<0.05$ and ${ }^{* *} \mathrm{P}<0.01$. (D) Effects of $\mathrm{BA}(50 \mu \mathrm{M})$ on gemcitabine $(5 \mu \mathrm{M})$ treatment-induced stemness were measured by western blot analysis. (E) Effects of BA $(50 \mu \mathrm{M})$ combined with gemcitabine $(5 \mu \mathrm{M})$ on the colony-forming ability of Panc-1 cells. (F and G) Effects of BA (50 $\mu \mathrm{M})$ combined with gemcitabine $(5 \mu \mathrm{M})$ on the apoptosis of Panc-1 cells. ${ }^{* *} \mathrm{P}<0.01$, compared with the control group. 7-AAD, 7-aminoactinomycin D; BA, betulinic acid; FITC, fluorescein isothiocyanate; Oct4, octamer-binding protein 4; RT-qPCR, reverse transcription-quantitative polymerase chain reaction; Sox2, SRY-box 2.

effectively inhibit invasion (Fig. 5D-F) and tumorsphere formation (Fig. 5G-I) in Mia PaCa-2-siControl and Panc-1-siControl cells. Conversely, Mia PaCa-2-siAMPK and Panc-1-siAMPK cells exhibited a slightly higher capacity for invasion and tumorsphere formation, which was not suppressed by BA treatment. Furthermore, this study analyzed whether BA could abrogate the expression of master pluripotency inducers (Sox2, Oct4 and Nanog) and EMT markers (E-cadherin and vimentin) in the absence of AMPK. As shown in Fig. 5B and C, BA treatment not only suppressed the expression of Sox 2, Oct4, Nanog and vimentin, but also increased the expression of E-cadherin in Mia PaCa-2-siControl and Panc-1-siControl cells; however, no alterations were detected in Mia PaCa-2-siAMPK and Panc-1-siAMPK cells. Similar results were also determined with regards to other stemness markers (CD133, ALDH1 and EpCAM; data not shown). Collectively, these results indicated that BA may inhibit invasion and tumorsphere formation of pancreatic cancer cells, and regulate the expression levels of Sox2, Oct4, Nanog and EMT markers in an AMPK-dependent manner.
$B A$ reverses stemness induced by gemcitabine and enhances the sensitivity of pancreatic cancer cells to gemcitabine. Gemcitabine is the major chemotherapeutic agent currently used in the treatment of pancreatic cancer; however, chemoresistance is a serious issue that markedly affects the prognosis of patients. A previous study demonstrated that gemcitabine treatment induces stemness in pancreatic cancer cells (45), which may serve a critical role in resistance to gemcitabine. The present results revealed that gemcitabine treatment dose-dependently increased the expression levels of CSC markers, including Sox2, Oct4 and Nanog (Fig. 6A and B). Similar effects were observed on other stemness markers (CD133, ALDH1 and EpCAM; data not shown). Since BA markedly inhibited the stemness of cancer cells, this study further investigated whether it could attenuate gemcitabine-induced stemness and facilitate the antitumor effects of gemcitabine. Notably, BA reversed gemcitabine-induced stemness, as revealed by decreased Sox2, Oct4 and Nanog expression (Fig. 6C and D). Since Panc-1 cells are resistant to gemcitabine (46), Panc-1 cells were selected for further experiments. Notably, BA 
combined with gemcitabine was more effective at suppressing proliferation (Fig. 6E) and inducing apoptosis (Fig. 6F and G) of Panc-1 cells. Taken together, these data suggested that BA may be considered a sensitizer in gemcitabine treatment.

\section{Discussion}

The tumor biology of PDAC is conducive to early metastasis and recurrence, and contributes to chemoradiotherapy resistance (47). It has previously been reported that several tumor types, including pancreatic cancer, exhibit a minority of cells that display a stem-like phenotype; these cells have an elevated metastatic potential, thus contributing to tumor recurrence and chemoresistance (48). The present study indicated a vital role for PCSCs in metastasis and recurrence of pancreatic cancer, and suggested that targeting PCSCs may be a promising strategy for the treatment of this refractory malignancy. In addition, EMT triggers cancer metastasis, which enhances the invasion of cancer cells and impels them to disseminate into secondary tissue sites, forming micrometastatic lesions. Furthermore, the EMT process confers on these cancer cells acquired stem-like traits for self-renewal, with an enhanced proliferative capacity and an ability to form macroscopic metastases from micrometastatic lesions $(43,49)$. Therefore, there is a direct link between the EMT process and CSCs. Notably, the present results revealed that BA effectively inhibited EMT and stemness of pancreatic cancer cells, thus suggesting that BA may be an effective compound to suppress metastasis of pancreatic cancer via targeting PCSCs and EMT.

Although known molecular markers of the cancer stem-like phenotype are still being discovered, three transcription factors, namely Sox2, Oct4 and Nanog, have been strongly validated as master regulators in the maintenance of the cancer stem-like phenotype (8). Overexpression of Sox2, Oct4 and Nanog frequently occurs in poorly differentiated malignancies and overlap with the signatures of embryonic stem cells (50). It has previously been reported that inhibition of AMPK signaling results in activation of the Warburg effect, which further induces stemness during the reprogramming of somatic cells (51). Furthermore, activation of AMPK signaling, via a pharmacological strategy, is a metabolic barrier during the process of somatic cells transforming into stem cells, which cannot be bypassed even under a p53 deficiency (52), thus indicating the critical role of AMPK signaling in stemness. It has also been reported that Sox2-overexpressed breast cancer cells downregulate AMPK signaling and activate mTOR to maintain their cancer stem-like phenotypes (44). In the present study, to explore the relationship between Sox 2 and AMPK in pancreatic cancer, immunohistochemistry was conducted; the results indicated that there was an inverse association between P-AMPK and the key stemness regulator, Sox 2 . Immunohistochemistry also revealed that, compared with in normal pancreatic tissues, the expression levels of P-AMPK were significantly decreased in pancreatic cancer tissues. Conversely, the expression levels of Sox 2 were markedly elevated. Investigating the modulation of AMPK signaling and suppression of pancreatic cancer stemness, it was revealed that administration of BA not only enhanced the levels of P-AMPK, but also inhibited the expression and nuclear localization of Sox 2 in Mia PaCa-2 and Panc-1 cells, in order to restrain the stem-like phenotype. This study confirmed the finding whereby AMPK signaling exerts an essential role in modulating EMT and stemness of pancreatic cancer.

Gemcitabine has been used as a major therapy for the treatment of advanced pancreatic cancer; however, the majority of patients develop resistance during the initial period of treatment. The definite mechanism underlying chemoresistance remains to be determined. Recent reports have demonstrated that treatment with gemcitabine fortifies the stemness of cancer cells via the NAPDH oxidase/reactive oxygen species/nuclear factor- $\mathrm{\kappa B} / \mathrm{STAT} 3$ signaling cascade and the long non-coding RNA HOX transcript antisense RNA $(45,53)$. Similarly, the present data indicated that gemcitabine treatment promoted upregulation of stemness markers in $\mathrm{MiaPaCa}-2$ and Panc-1 pancreatic cancer cell lines. Notably, BA reversed gemcitabine-induced stemness and facilitated the antitumor effects of gemcitabine in pancreatic cancer cells; therefore, it may be considered a potential sensitizer for patients with pancreatic cancer.

BA is known to exert antidepressive (24), anti-inflammatory $(25,26)$ and anti-AIDs $(27,28)$ effects; in addition, it has hepatoprotective potential (29) and can alleviate NAFLD (35). Furthermore, its potential as a cancer preventive and therapeutic compound has been verified (30-34). Of particular interest is its direct and relatively selective cytotoxic effect on various tumor cells compared with normal or non-neoplastic cells (54). The present results revealed that BA may inhibit the proliferation, migration, invasion and tumorsphere formation of pancreatic cancer cells, regulate EMT, and alter the expression levels of Sox2, Oct4 and Nanog via activation of AMPK signaling. Furthermore, BA combined with gemcitabine exerted antitumor effects on pancreatic cancer cells. However, there are some limitations to the present study. These findings were based on in vitro experiments, which may not accurately reflect the physiological conditions in vivo. Therefore, BA warrants further functional studies and in vivo investigations, to determine whether it is an effective inhibitor of the stem-like phenotype in pancreatic cancer cells.

\section{Acknowledgements}

Not applicable.

\section{Funding}

The present study was supported by grants from the National Natural Science Foundation of China (grant nos. 81502528, 81572734, 81672434 and 81702916).

\section{Availability of data and materials}

The data and materials used during the present study are available from the corresponding author upon reasonable request.

\section{Authors' contributions}

LS, JC, QM and QX designed the experiments. LS and JC conducted the majority of the experiments. $\mathrm{KC}$ analyzed the data. $\mathrm{LC}, \mathrm{CZ}$ and $\mathrm{BY}$ organized the figures and contributed to data analysis. LS and JC wrote the manuscript, and QM 
and QX reviewed it. WQ, JL, WD, JM, DQ, EW, ZW and QL contributed to the collection of human specimens and revised the manuscript. All authors read and approved the final manuscript.

\section{Ethics approval and consent to participate}

All experimental protocols were approved by the Ethical Committee of The First Affiliated Hospital of Xi'an Jiaotong University. Written informed consent was obtained from the patients.

\section{Patient consent for publication}

The authors declare that the patients provided written informed consent for the publication of any associated data in the present study.

\section{Competing interests}

The authors declare that they have no competing interests.

\section{References}

1. Siegel RL, Miller KD and Jemal A: Cancer statistics, 2016. CA Cancer J Clin 66: 7-30, 2016

2. Gillen S, Schuster T, Meyer Zum Büschenfelde C, Friess H and Kleeff J: Preoperative/neoadjuvant therapy in pancreatic cancer: A systematic review and meta-analysis of response and resection percentages. PLoS Med 7: e1000267, 2010.

3. Siegel R, Ma J, Zou Z and Jemal A: Cancer statistics, 2014. CA Cancer J Clin 64: 9-29, 2014.

4. Kamisawa T, Isawa T, Koike M, Tsuruta $\mathrm{K}$ and Okamoto A: Hematogenous metastases of pancreatic ductal carcinoma. Pancreas 11: 345-349, 1995.

5. Gattinoni L, Klebanoff CA and Restifo NP: Paths to stemness: Building the ultimate antitumour T cell. Nat Rev Cancer 12: 671-684, 2012.

6. Magee JA, Piskounova E and Morrison SJ: Cancer stem cells: Impact, heterogeneity, and uncertainty. Cancer Cell 21: 283-296, 2012.

7. Clevers H: The cancer stem cell: Premises, promises and challenges. Nat Med 17: 313-319, 2011.

8. Sengupta S, Nagalingam A, Muniraj N, Bonner MY, Mistriotis P, Afthinos A, Kuppusamy P, Lanoue D, Cho S, Korangath P, et al: Activation of tumor suppressor LKB1 by honokiol abrogates cancer stem-like phenotype in breast cancer via inhibition of oncogenic Stat3. Oncogene 36: 5709-5721, 2017.

9. Thiery JP, Acloque H, Huang RY and Nieto MA: Epithelial-mesenchymal transitions in development and disease. Cell 139: 871-890, 2009.

10. Mani SA, Guo W, Liao MJ, Eaton EN, Ayyanan A, Zhou AY, Brooks M, Reinhard F, Zhang CC, Shipitsin M, et al: The epithelial-mesenchymal transition generates cells with properties of stem cells. Cell 133: 704-715, 2008.

11. Chaffer CL, Marjanovic ND, Lee T, Bell G, Kleer CG, Reinhardt F, D'Alessio AC, Young RA and Weinberg RA: Poised chromatin at the ZEB1 promoter enables breast cancer cell plasticity and enhances tumorigenicity. Cell 154: 61-74, 2013.

12. Abel EV and Simeone DM: Biology and clinical applications of pancreatic cancer stem cells. Gastroenterology 144: 1241-1248, 2013.

13. Hardie DG: AMP-activated/SNF1 protein kinases: Conserved guardians of cellular energy. Nat Rev Mol Cell Biol 8: 774-785, 2007.

14. Young LH, Li J, Baron SJ and Russell RR: AMP-activated protein kinase: A key stress signaling pathway in the heart. Trends Cardiovasc Med 15: 110-118, 2005.

15. Zheng X, Chi J, Zhi J, Zhang H, Yue D, Zhao J, Li D, Li Y, Gao M and Guo J: Aurora-A-mediated phosphorylation of LKB1 compromises LKB1/AMPK signaling axis to facilitate NSCLC growth and migration. Oncogene 37: 502-511, 2018.
16. Shi WY, Xiao D, Wang L, Dong LH, Yan ZX, Shen ZX, Chen SJ, Chen Y and Zhao WL: Therapeutic metformin/AMPK activation blocked lymphoma cell growth via inhibition of mTOR pathway and induction of autophagy. Cell Death Dis 3: e275, 2012

17. Handy JA, Saxena NK, Fu P, Lin S, Mells JE, Gupta NA and Anania FA: Adiponectin activation of AMPK disrupts leptin-mediated hepatic fibrosis via suppressors of cytokine signaling (SOCS-3). J Cell Biochem 110: 1195-1207, 2010.

18. da Silva Morais A, Abarca-Quinones J, Guigas B, Viollet B, Stärkel P, Horsmans Y and Leclercq IA: Development of hepatic fibrosis occurs normally in AMPK-deficient mice. Clin Sci (Lond) 118: 411-420, 2009.

19. Kahn BB, Alquier T, Carling D and Hardie DG: AMP-activated protein kinase: Ancient energy gauge provides clues to modern understanding of metabolism. Cell Metab 1: 15-25, 2005.

20. MenendezJA,JovenJ,CufíS,Corominas-FajaB,Oliveras-Ferraros $\mathrm{C}$, Cuyàs $\mathrm{E}$, Martin-Castillo $\mathrm{B}$, López-Bonet $\mathrm{E}$, Alarcón $\mathrm{T}$ and Vazquez-Martin A: The Warburg effect version 2.0: Metabolic reprogramming of cancer stem cells. Cell Cycle 12: 1166-1179, 2013.

21. Cheng X, Kim JY, Ghafoory S, Duvaci T, Rafiee R, Theobald J, Alborzinia H, Holenya P, Fredebohm J, Merz KH, et al: Methylisoindigo preferentially kills cancer stem cells by interfering cell metabolism via inhibition of LKB1 and activation of AMPK in PDACs. Mol Oncol 10: 806-824, 2016.

22. Lonardo E, Cioffi M, Sancho P, Sanchez-Ripoll Y, Trabulo SM, Dorado J, Balic A, Hidalgo M and Heeschen C: Metformin targets the metabolic achilles heel of human pancreatic cancer stem cells. PLoS One 8: e76518, 2013.

23. Bao B, Wang Z, Ali S, Ahmad A, Azmi AS, Sarkar SH, Banerjee S, Kong D, Li Y, Thakur S, et al: Metformin inhibits cell proliferation, migration and invasion by attenuating CSC function mediated by deregulating miRNAs in pancreatic cancer cells. Cancer Prev Res (Phila) 5: 355-364, 2012.

24. Machado DG, Cunha MP, Neis VB, Balen GO, Colla A, Bettio LE, Oliveira A, Pazini FL, Dalmarco JB, Simionatto EL, et al: Antidepressant-like effects of fractions, essential oil, carnosol and betulinic acid isolated from Rosmarinus officinalis L. Food Chem 136: 999-1005, 2013.

25. Tsai JC,Peng WH,Chiu TH,LaiSC and Lee CY: Anti-inflammatory effects of Scoparia dulcis L. and betulinic acid. Am J Chin Med 39: 943-956, 2011.

26. Viji V, Helen A and Luxmi VR: Betulinic acid inhibits endotoxin-stimulated phosphorylation cascade and pro-inflammatory prostaglandin $\mathrm{E}(2)$ production in human peripheral blood mononuclear cells. Br J Pharmacol 162: 1291-1303, 2011.

27. Qian K, Bori ID, Chen CH, Huang L and Lee KH: Anti-AIDS agents 90 . novel C-28 modified bevirimat analogues as potent HIV maturation inhibitors. J Med Chem 55: 8128-8136, 2012

28. Fujioka T, Kashiwada Y, Kilkuskie RE, Cosentino LM, Ballas LM, Jiang JB, Janzen WP, Chen IS and Lee KH: Anti-AIDS agents, 11. Betulinic acid and platanic acid as anti-HIV principles from Syzigium claviflorum, and the anti-HIV activity of structurally related triterpenoids. J Nat Prod 57: 243-247, 1994.

29. Jain M, Kapadia R, Jadeja RN, Thounaojam MC, Devkar RV and Mishra SH: Hepatoprotective potential of Tecomella undulata stem bark is partially due to the presence of betulinic acid. J Ethnopharmacol 143: 194-200, 2012.

30. Wang P, Li Q, Li K, Zhang X, Han Z, Wang J, Gao D and Li J: Betulinic acid exerts immunoregulation and anti-tumor effect on cervical carcinoma (U14) tumor-bearing mice. Pharmazie 67: 733-739, 2012.

31. Liu Y and Luo W: Betulinic acid induces Bax/Bak-independent cytochrome $\mathrm{c}$ release in human nasopharyngeal carcinoma cells. Mol Cells 33: 517-524, 2012.

32. Chintharlapalli S, Papineni S, Lei P, Pathi S and Safe S: Betulinic acid inhibits colon cancer cell and tumor growth and induces proteasome-dependent and -independent downregulation of specificity proteins (Sp) transcription factors. BMC Cancer 11: 371, 2011.

33. Gao Y, Jia Z, Kong X, Li Q, Chang DZ, Wei D, Le X, Suyun H, Huang S, Wang L, et al: Combining betulinic acid and mithramycin a effectively suppresses pancreatic cancer by inhibiting proliferation, invasion, and angiogenesis. Cancer Res 71: 5182-5193, 2011.

34. Li L, Du Y, Kong X, Li Z, Jia Z, Cui J, Gao J, Wang G and $\mathrm{Xie} \mathrm{K}$ : Lamin B1 is a novel therapeutic target of betulinic acid in pancreatic cancer. Clinical Cancer Res 19: 4651-4661, 2013.

35. Quan HY, Kim DY, Kim SJ, Jo HK, Kim GW and Chung SH: Betulinic acid alleviates non-alcoholic fatty liver by inhibiting SREBP1 activity via the AMPK-mTOR-SREBP signaling pathway. Biochem Pharmacol 85: 1330-1340, 2013. 
36. Ma J, Duan W, Han S, Lei J, Xu Q, Chen X, Jiang Z, Nan L, $\mathrm{Li}$ J, Chen K, et al: Ginkgolic acid suppresses the development of pancreatic cancer by inhibiting pathways driving lipogenesis. Oncotarget 6: 20993-21003, 2015.

37. Lei J, Ma J, Ma Q, Li X, Liu H, Xu Q, Duan W, Sun Q, Xu $\mathrm{J}, \mathrm{Wu} \mathrm{Z}$, et al: Hedgehog signaling regulates hypoxia induced epithelial to mesenchymal transition and invasion in pancreatic cancer cells via a ligand-independent manner. Mol Cancer 12: 66, 2013.

38. Lei J, Huo X, Duan W, Xu Q, Li R, Ma J, Li X, Han L, Li W, Sun $\mathrm{H}$, et al: $\alpha$-Mangostin inhibits hypoxia-driven ROS-induced PSC activation and pancreatic cancer cell invasion. Cancer Lett 347: 129-138, 2014.

39. Schmittgen TD and Livak KJ: Analyzing real-time PCR data by the comparative C(T) method. Nat Protoc 3: 1101-1108, 2008.

40. Özdemir BC, Pentcheva-Hoang T, Carstens JL, Zheng X, Wu CC, Simpson TR, Laklai H, Sugimoto H, Kahlert C, Novitskiy SV, et al: Depletion of carcinoma-associated fibroblasts and fibrosis induces immunosuppression and accelerates pancreas cancer with reduced survival. Cancer Cell 25: 719-734, 2014.

41. Duan W, Chen K, Jiang Z, Chen X, Sun L, Li J, Lei J, Xu Q, Ma J, Li X, et al: Desmoplasia suppression by metformin-mediated AMPK activation inhibits pancreatic cancer progression. Cancer Lett 385: 225-233, 2017.

42. Chen K, Qian W, Li J, Jiang Z, Cheng L, Yan B, Cao J, Sun L, Zhou C, Lei M, et al: Loss of AMPK activation promotes the invasion and metastasis of pancreatic cancer through an HSF1-dependent pathway. Mol Oncol 11: 1475-1492, 2017.

43. Thiery JP: Epithelial-mesenchymal transitions in development and pathologies. Curr Opin Cell Biol 15: 740-746, 2003.

44. Corominas-Faja $\mathrm{B}$, Cufí $\mathrm{S}$, Oliveras-Ferraros $\mathrm{C}$, Cuyàs $\mathrm{E}$, López-Bonet E, Lupu R, Alarcón T, Vellon L, Iglesias JM, Leis $\mathrm{O}$, et al: Nuclear reprogramming of luminal-like breast cancer cells generates Sox2-overexpressing cancer stem-like cellular states harboring transcriptional activation of the mTOR pathway. Cell Cycle 12: 3109-3124, 2013.

45. Zhang Z, Duan Q, Zhao H, Liu T, Wu H, Shen Q, Wang C and Yin T: Gemcitabine treatment promotes pancreatic cancer stemness through the Nox/ROS/NF- $\kappa \mathrm{B} / \mathrm{STAT} 3$ signaling cascade. Cancer Lett 382: 53-63, 2016.
46. Cao J, Yang J, Ramachandran V, Arumugam T, Deng D, Li Z, Xu L and Logsdon CD: TM4SF1 promotes gemcitabine resistance of pancreatic cancer in vitro and in vivo. PLoS One 10: e0144969, 2015.

47. Kamisawa T, Wood LD, Itoi $\mathrm{T}$ and Takaori K: Pancreatic cancer. Lancet 388: 73-85, 2016.

48. Zhao J, Li J, Schlößer HA, Popp F, Popp MC, Alakus H, Jauch KW, Bruns CJ and Zhao Y: Targeting cancer stem cells and their Niche: Current therapeutic implications and challenges in pancreatic cancer. Stem Cells Int 2017: 6012810, 2017.

49. Kondo M, Wagers AJ, Manz MG, Prohaska SS, Scherer DC, Beilhack GF, Shizuru JA and Weissman IL: Biology of hematopoietic stem cells and progenitors: Implications for clinical application. Annu Rev Immunol 21: 759-806, 2003.

50. Ben-Porath I, Thomson MW, Carey VJ, Ge R, Bell GW, Regev A and Weinberg RA: An embryonic stem cell-like gene expression signature in poorly differentiated aggressive human tumors. Nat Genet 40: 499-507, 2008.

51. Faubert B, Boily G, Izreig S, Griss T, Samborska B, Dong Z, Dupuy F, Chambers C, Fuerth BJ, Viollet B, et al: AMPK is a negative regulator of the Warburg effect and suppresses tumor growth in vivo. Cell Metab 17: 113-124, 2013.

52. Vazquez-Martin A, Vellon L, Quirós PM, Cufí S, Ruiz de Galarreta E, Oliveras-Ferraros C, Martin AG, Martin-Castillo B, López-Otín C and Menendez JA: Activation of AMP-activated protein kinase (AMPK) provides a metabolic barrier to reprogramming somatic cells into stem cells. Cell Cycle 11: 974-989, 2012.

53. Wang L, Dong P, Wang W, Huang M and Tian B: Gemcitabine treatment causes resistance and malignancy of pancreatic cancer stem-like cells via induction of lncRNA HOTAIR. Exp Ther Med 14: 4773-4780, 2017.

54. Pisha E, Chai H, Lee IS, Chagwedera TE, Farnsworth NR, Cordell GA, Beecher CW, Fong HH, Kinghorn AD, Brown DM, et al: Discovery of betulinic acid as a selective inhibitor of human melanoma that functions by induction of apoptosis. Nat Med 1: 1046-1051, 1995.

c) (i) $\Theta$ This work is licensed under a Creative Commons cc) Attribution-NonCommercial-NoDerivatives 4.0 International (CC BY-NC-ND 4.0) License. 